\title{
Enantioselective, Cyclopentene-Forming Annulations via NHC-Catalyzed Benzoin-Oxy-Cope Reactions
}

\author{
Pei-Chen Chiang, Juthanat Kaeobamrung, and Jeffrey W. Bode* \\ Department of Chemistry and Biochemistry, University of California, \\ Santa Barbara, CA 93106-9510
}

\section{Supporting Information}

General Methods. All reactions utilizing air- or moisture-sensitive reagents were performed in dried glassware under an atmosphere of dry Ar. Dichloroethane (DCE) and $\mathrm{CH}_{2} \mathrm{Cl}_{2}$ were distilled over $\mathrm{CaH}_{2}$. EtOH was distilled over Mg. THF were dried by passage over activated alumina under Ar atmosphere. Cinnamaldehyde, trans-2-hexene-1-al, and 1,8-diazabicyclo[5.4.0]undec7-ene (DBU) were purified by vacuum distillation prior to use. Trans-3-(2-furyl)acrolein was purified by sublimation. Other reagents were used without further purification. Thin layer chromatography (TLC) was performed on Merck precoated plates (silica gel $60 \mathrm{~F}_{254}$, Art 5715, $0.25 \mathrm{~mm}$ ) and were visualized by fluorescence quenching under UV light or by staining with phosphomolybdic acid. Silica-gel preparative thin-layer chromatography (PTLC) was performed using plates prepared from Merck Kieselgel $60 \mathrm{PF}_{254}$ (Art 7747). Column chromatography was performed on E. Merck Silica Gel 60 (230-400 Mesh) using a forced flow of 0.5-1.0 bar. ${ }^{1} \mathrm{H}$ NMR (400 MHz) and ${ }^{13} \mathrm{C}$ NMR (100 MHz) were measured on a Varian Unity 400 spectrometer. Chemical shifts are expressed in parts per million ( $\mathrm{ppm}$ ) downfield from residual solvent peaks and coupling constants are reported as Hertz $(\mathrm{Hz})$. Splitting patterns are indicated as follows: br, broad; s, singlet; d, doublet; ad, approximate doublet; t, triplet; q, quartet; m, multiplet; asterisks (*) indicate peaks arising from the minor diastereomers. Infrared (IR) spectra were recorded on a JASCO FT:IR-430 spectrophotometer and are reported as wavenumber $\left(\mathrm{cm}^{-1}\right)$. Optical rotations were measured on a JASCO DIP-1000 polarimeter operating at the sodium D line with a $100 \mathrm{~mm}$ path length cell, and are reported as follows: $[\alpha]_{\mathrm{D}}^{\mathrm{T}}$ (concentration $(\mathrm{g} / 100 \mathrm{~mL})$, solvent).

HPLC Conditions. Column, Diacel Chiralpak AD-H $(4.6 \times 250 \mathrm{~mm})$; eluent: hexanes:iPrOH and hexanes:EtOH; flow rate $1.0 \mathrm{~mL} / \mathrm{min}$; detection: $254 \mathrm{~nm}$.

SFC Conditions. Column, Diacel Chiralpak AS-H, $(4.6 \times 250 \mathrm{~mm})$; eluent: $\mathrm{CO}_{2}: \mathrm{MeOH}$; oven temperature: $40{ }^{\circ} \mathrm{C}$; pressure 100 bar; flow rate $2.0 \mathrm{~mL} / \mathrm{min}$; detection: $254 \mathrm{~nm}$. 


\section{General procedure for NHC-catalyzed, enantioselective benzoin-oxy-Cope reactions}

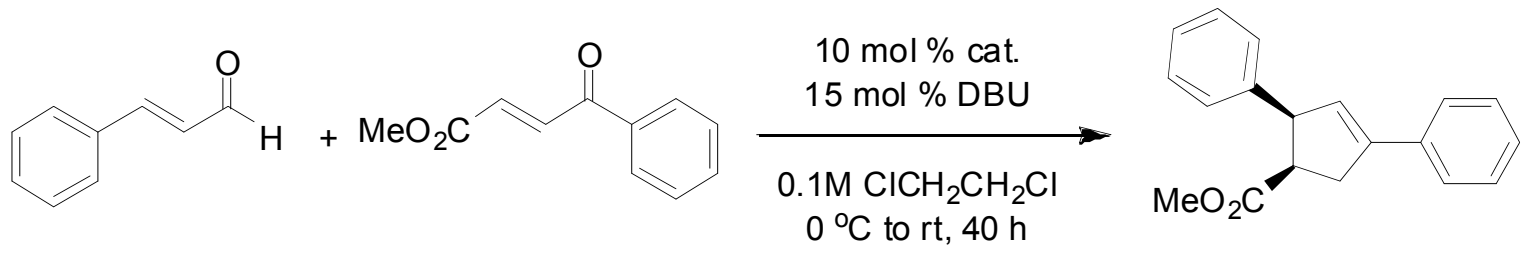

The reaction of trans-methyl-4-oxo-4-phenylbut-2-enoate and cinnamaldehyde is representative: Into an oven dried $10.0 \mathrm{~mL}$ vial was added the 4-oxoenoate (95.1 mg, $0.50 \mathrm{mmol}, 1.00$ equiv) and triazolium catalyst 1 (18.3 mg, $0.05 \mathrm{mmol}, 0.10$ equiv). The vial was sealed with a septum and $5.0 \mathrm{~mL}$ dichloroethane $(0.1 \mathrm{M})$ and cinnamaldehyde $(69.4 \mu \mathrm{L}, 0.55 \mathrm{mmol}, 1.1$ equiv) were added via syringe. The solution was stirred at $0{ }^{\circ} \mathrm{C}$ for 15 minutes before DBU $(11.3 \mu \mathrm{L}, 0.075$ mmol, 0.15 equiv) was added. The resulting solution was stirred at $0{ }^{\circ} \mathrm{C}$ at least $6 \mathrm{~h}$, followed by warming to $\mathrm{rt}$ for $40 \mathrm{~h}$ total reaction time. The reaction mixture was concentrated under reduced pressure, and the residue was purified by column chromatography ( $9: 1$ hexanes:EtOAc) to afford the cyclopentene product as a white solid (109 $\mathrm{mg}, 78 \%$ yield, 9:1 dr).

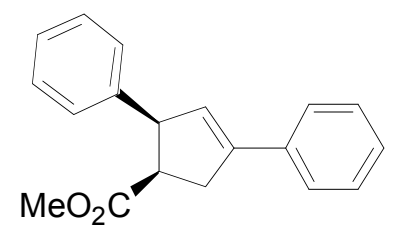

cis-1,3(S)-Diphenyl-4(R)-methoxycarbonylcyclopent-1-ene (Table 1, entry 1). Prepared according to the general procedure from cinnamaldehyde and trans-methyl-4-oxo-4-phenylbut-2enoate using $10 \mathrm{~mol} \% 1$ as the catalyst in $78 \%$ yield $(9: 1 \mathrm{dr})$ as a white solid. $[\alpha]_{\mathrm{D}}{ }^{20}(\mathrm{c} 1.25$, $\mathrm{CHCl}_{3}$ ): +139.5; mp: $107-108{ }^{\circ} \mathrm{C} ;{ }^{1} \mathrm{H}$ NMR (400 MHz, $\left.\mathrm{CDCl}_{3}\right) \delta$ 7.58-7.52 (m, 2H), 7.43-7.18 (m, 8H), 6.19 (s, 1H), 4.47-4.43 (ad, 1H), 3.82-3.75 (m, 1H), 3.49-3.43 (m, 1H), $3.28(\mathrm{~s}, 3 \mathrm{H})$, 2.97-2.91 (dd, 1H, $J=16.1,9.0 \mathrm{~Hz}) ;{ }^{13} \mathrm{C} \mathrm{NMR}\left(100 \mathrm{MHz}, \mathrm{CDCl}_{3}\right) \delta 173.4,142.7,140.3,135.7$, $128.8,128.7^{*}, 128.3,127.9,127.7,127.3^{*}, 126.8,126.1^{*}, 126.0,125.9,54.7,51.4,48.8,34.6$; IR (thin film) v 3048, 3027, 2925, 2898, 2855, 1731, 1447, 1227, 1200, 1169, $1150 \mathrm{~cm}^{-1}$; HRMS (EI) for $\mathrm{C}_{19} \mathrm{H}_{18} \mathrm{O}_{2}$ calcd. $\left(\mathrm{M}^{+}\right)$: 278.1307, found: 278.1313 ; $>99 \%$ ee (major, cis), $69 \%$ ee (minor, trans) as determined by HPLC (AD-H, 60:1 hexanes:EtOH), $t_{\mathrm{r}}$ (major) $=9.1$ and 11.9 min, $t_{\mathrm{r}}$ $($ minor $)=8.2$ and $11.1 \mathrm{~min}$. 
Racemic

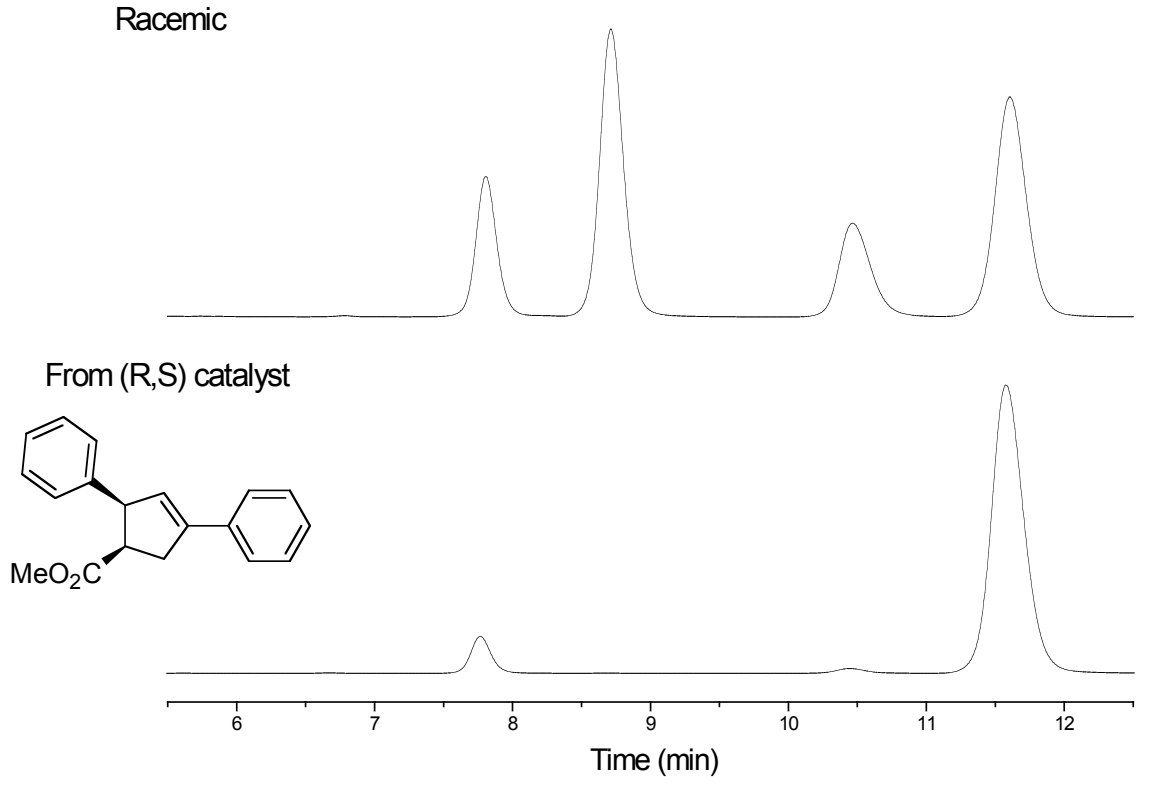

NOE Experiment
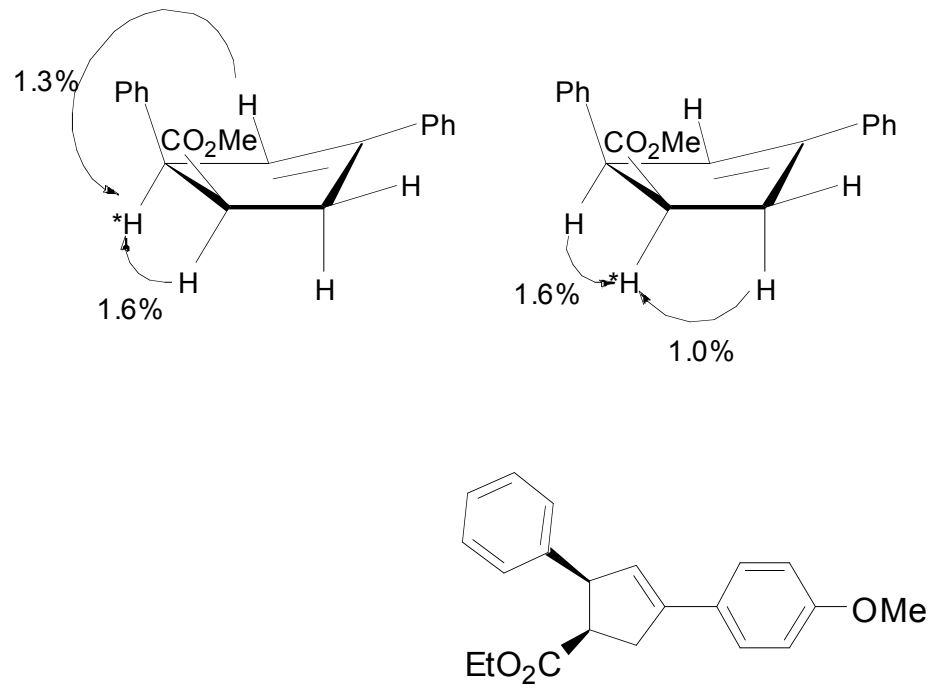

cis-4(R)-Ethoxycarbonyl-1-(4-methoxyphenyl)-3(S)-phenylcyclopent-1-ene (Table 1, entry 2).

Prepared according to the general procedure from cinnamaldehyde and trans-ethyl-4-(4methoxyphenyl)-4-oxobut-2-enoate using $10 \mathrm{~mol} \% \mathbf{1}$ as the catalyst in 58\% yield (5:1 dr) as a white solid. $[\alpha]_{\mathrm{D}}{ }^{20}$ (c 1.00, $\mathrm{CHCl}_{3}$ ): +148.8; mp: $110-111{ }^{\circ} \mathrm{C} ;{ }^{1} \mathrm{H}$ NMR $\left(400 \mathrm{MHz}, \mathrm{CDCl}_{3}\right) \delta$ 7.50-7.49 (m, 2H), 7.47-7.15 (m, 5H), 6.93-6.89 (m, 2H), $6.03(\mathrm{~s}, 1 \mathrm{H}), 4.42-4.38$ (dt, 1H, $J=$ 9.8, $2.8 \mathrm{~Hz}), 3.84(\mathrm{~s}, 3 \mathrm{H}), 3.77-3.61(\mathrm{~m}, 3 \mathrm{H}), 3.44-3.38(\mathrm{~m}, 1 \mathrm{H}), 2.92-2.85(\mathrm{dd}, 1 \mathrm{H}, J=11.4$, 
$9.1 \mathrm{~Hz}), 0.92-0.88(\mathrm{t}, 3 \mathrm{H}, J=7.2 \mathrm{~Hz}) ;{ }^{13} \mathrm{C} \mathrm{NMR}\left(100 \mathrm{MHz}, \mathrm{CDCl}_{3}\right) \delta 173.1,159.4,141.9$, $140.8,128.9,128.6,128.2,127.3,127.2,125.0,114.0,60.4,55.5,54.7,48.7,34.9$, 14.0; IR (thin film) $v 2932,1730,1606,1513,1256,1197,1177,1037 \mathrm{~cm}^{-1}$; HRMS (EI) for $\mathrm{C}_{21} \mathrm{H}_{22} \mathrm{O}_{3}$ calcd. $\left(\mathrm{M}^{+}\right)$: 322.1569, found: 322.1570; >99\% ee (major, cis), 68\% ee (minor, trans) as determined by HPLC $(\mathrm{AD}-\mathrm{H}, 60: 1$ hexanes:EtOH $), t_{\mathrm{r}}$ (major) $=19.6$ and $21.8 \mathrm{~min}, t_{\mathrm{r}}($ minor $)=13.2$ and 16.2 min.

Racemic
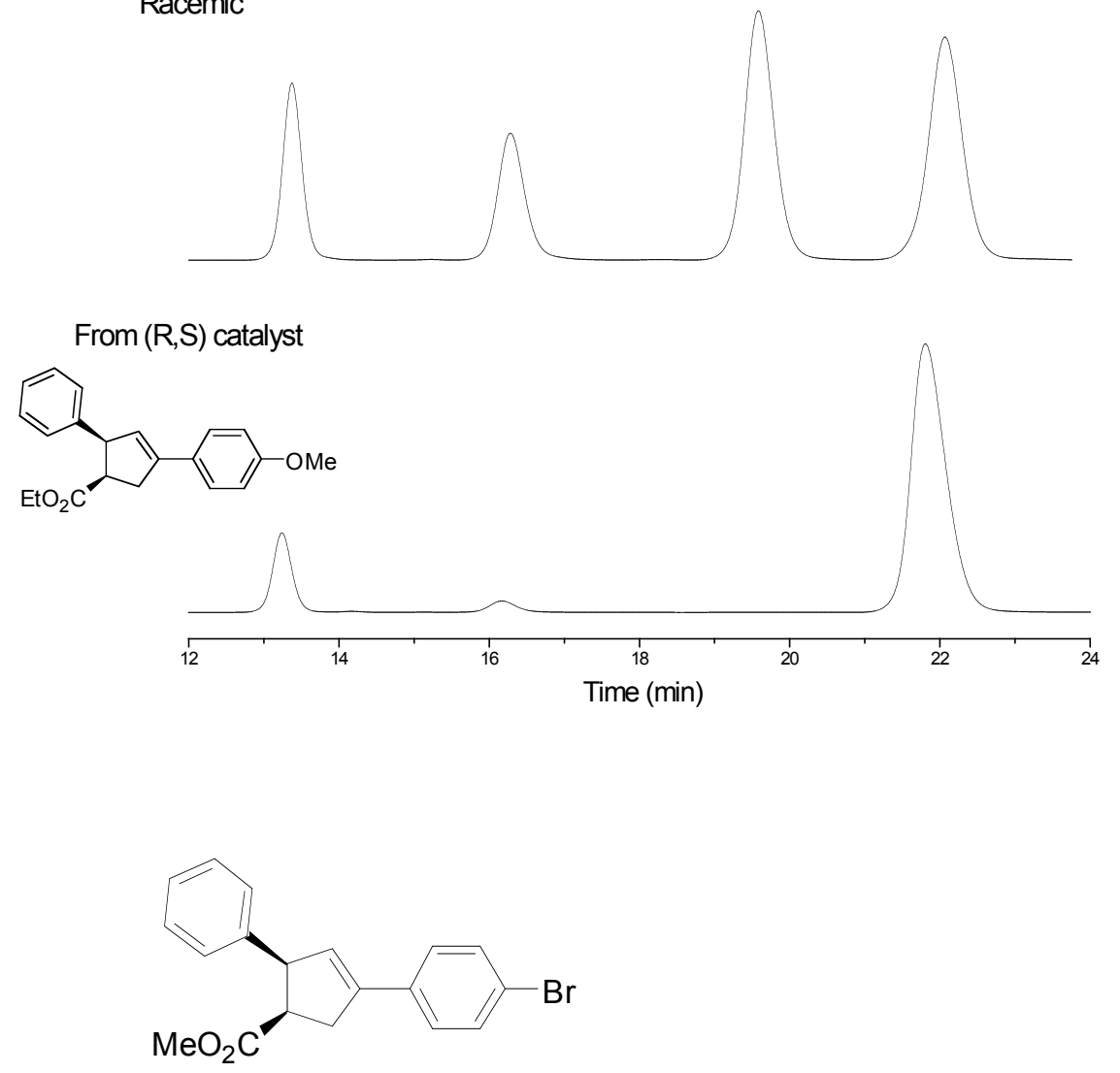

cis-1-(4-Bromophenyl)-4(R)-methoxycarbonyl-3(S)-phenylcyclopent-1-ene (Table 1, entry 3). Prepared according to the general procedure from cinnamaldehyde and trans-methyl-4-(4bromophenyl)-4-oxobut-2-enoate using $10 \mathrm{~mol} \% 1$ as the catalyst in 50\% yield (11:1 dr) as a white solid. $[\alpha]_{\mathrm{D}}{ }^{20}$ (c 1.07, $\left.\mathrm{CHCl}_{3}\right):+113.2$; mp: 91-92 ${ }^{\circ} \mathrm{C} ;{ }^{1} \mathrm{H}$ NMR $\left(400 \mathrm{MHz}, \mathrm{CDCl}_{3}\right) \delta 7.51-$ 7.49 (ad, 2H), 7.41-7.35 (m, 2H), 7.28-7.26 (m, 3H), 7.24-7.14 (ad, 2H), 6.16 (s, 1H), 4.43$4.41(\mathrm{ad}, 1 \mathrm{H}), 3.77-3.75(\mathrm{~m}, 1 \mathrm{H}), 3.44-3.39(\mathrm{~m}, 1 \mathrm{H}), 3.25(\mathrm{~s}, 3 \mathrm{H}), 2.91-2.85(\mathrm{~m}, 1 \mathrm{H})$; ${ }^{13} \mathrm{C} \mathrm{NMR}$ $\left(100 \mathrm{MHz}, \mathrm{CDCl}_{3}\right) \delta 173.3,141.6,140.0,134.6,131.7,128.8,128.6,128.3,127.7,127.6,127.5$, 
$127.3,121.7,55.3^{*}, 54.7,52.2^{*}, 51.4,48.7,37.0^{*}, 34.6$; IR (thin film) v 2947, 1735, 1638, 1489, 1200, $1168 \mathrm{~cm}^{-1}$; HRMS (EI) for $\mathrm{C}_{19} \mathrm{H}_{17} \mathrm{BrO}_{2}$ calcd. $\left(\mathrm{M}^{+}\right)$: 356.0412, found: 356.0407 ; $>99 \%$ ee (major, cis), 79\% ee (minor, trans) as determined by HPLC (AD-H, 60:1 hexanes:EtOH), $t_{\mathrm{r}}$ $($ major $)=17.3$ and $20.3 \mathrm{~min}, t_{\mathrm{r}}($ minor $)=11.0$ and $16.2 \mathrm{~min}$.

Racemic

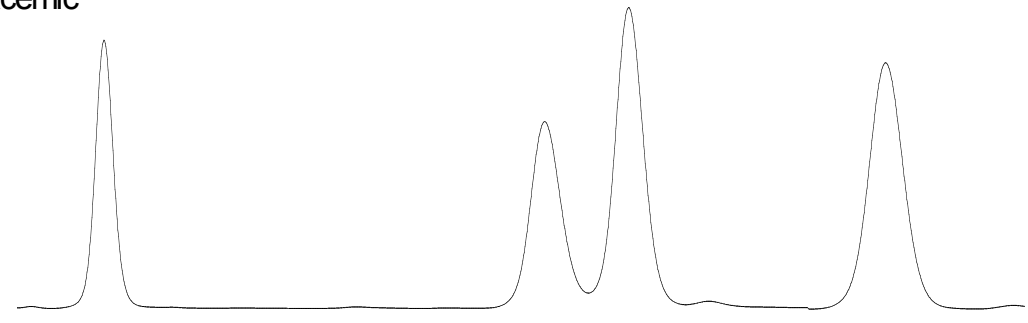

From $(R, S)$ catalyst
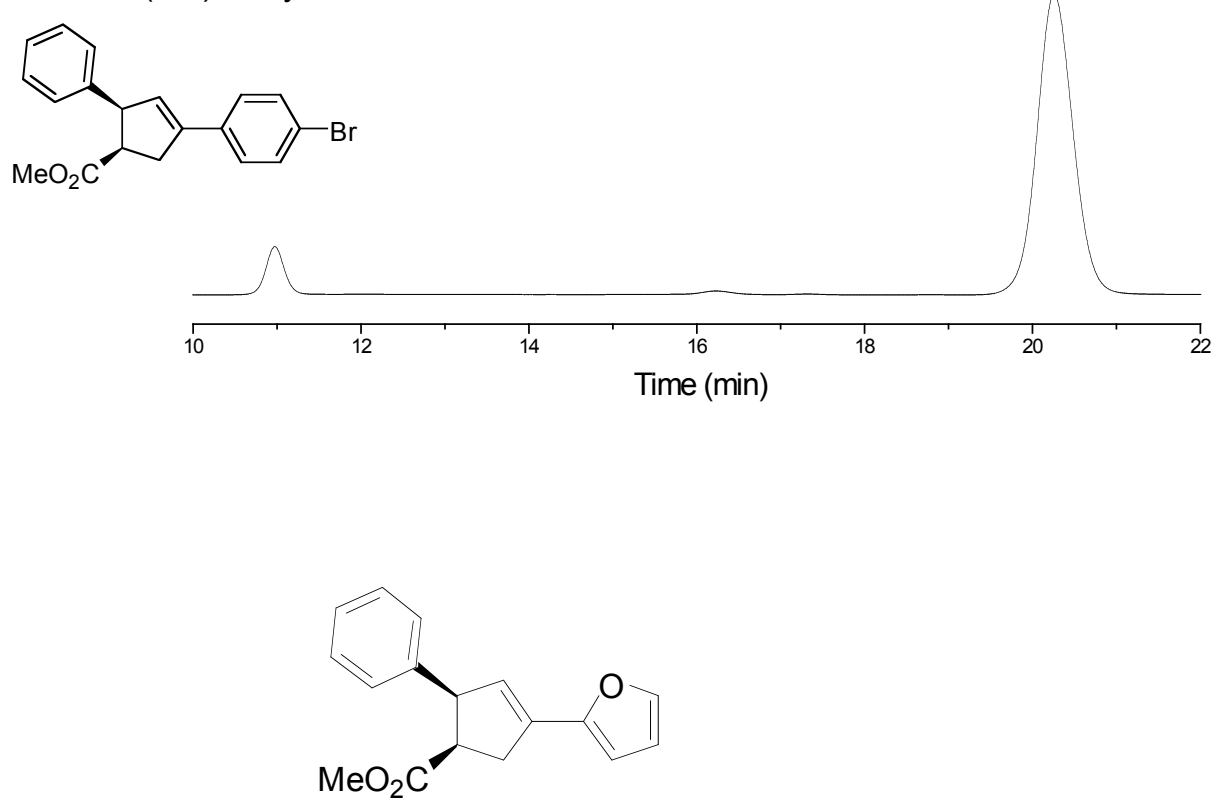

cis-1-(Furan-2-yl)-4(R)-methoxycarbonyl-3(S)-phenylcyclopent-1-ene (Table 1, entry 4). Prepared according to the general procedure from cinnamaldehyde and trans-methyl-4-(4-furan2-yl)-4-oxobut-2-enoate using $10 \mathrm{~mol} \% \mathbf{1}$ as the catalyst in $93 \%$ yield (>20:1 dr) as a light yellow solid. $[\alpha]_{\mathrm{D}}{ }^{20}\left(\mathrm{c} 1.09, \mathrm{CHCl}_{3}\right):+136.5$; mp: $126-127{ }^{\circ} \mathrm{C} ;{ }^{1} \mathrm{H}$ NMR $\left(400 \mathrm{MHz}, \mathrm{CDCl}_{3}\right) \delta$ $7.42(\mathrm{~s}, 1 \mathrm{H}), 7.28-7.14(\mathrm{~m}, 6 \mathrm{H}), 6.44-6.43(\mathrm{~m}, 1 \mathrm{H}), 6.35-6.34(\mathrm{~d}, 1 \mathrm{H}, J=2.8 \mathrm{~Hz}), 6.01(\mathrm{~s}, 1 \mathrm{H})$, 4.43-4.41 (ad, 1H, $J=9.7 \mathrm{~Hz}), 3.73-3.71(\mathrm{dd}, 1 \mathrm{H}, J=18.1,18.0 \mathrm{~Hz}), 3.35-3.29(\mathrm{~m}, 1 \mathrm{H}), 3.23$ (s, 3H), 2.85-2.78 (dd, $1 \mathrm{H}, J=11.5,9.0 \mathrm{~Hz}) ;{ }^{13} \mathrm{C} \mathrm{NMR}\left(100 \mathrm{MHz}, \mathrm{CDCl}_{3}\right) \delta 173.3,151.4$, $142.5,140.1,133.0,128.7,128.3,127.3,125.4,111.4,107.7,54.7,51.4,48.8,33.9$; IR (thin 
film) $v$ 2906, 1728, 1453, 1440, 1363, 1201, 1171, $1159 \mathrm{~cm}^{-1}$; HRMS (EI) for $\mathrm{C}_{17} \mathrm{H}_{16} \mathrm{O}_{3}$ calcd. $\left(\mathrm{M}^{+}\right)$: 268.1099, found: 268.1092; 98\% ee (major, cis), as determined by HPLC (AD-H, 9:1 hexanes: $\mathrm{PPrOH}), t_{\mathrm{r}}($ major $)=4.8$ and $5.2 \mathrm{~min}, t_{\mathrm{r}}(\operatorname{minor})=5.5$ and $6.9 \mathrm{~min}$.
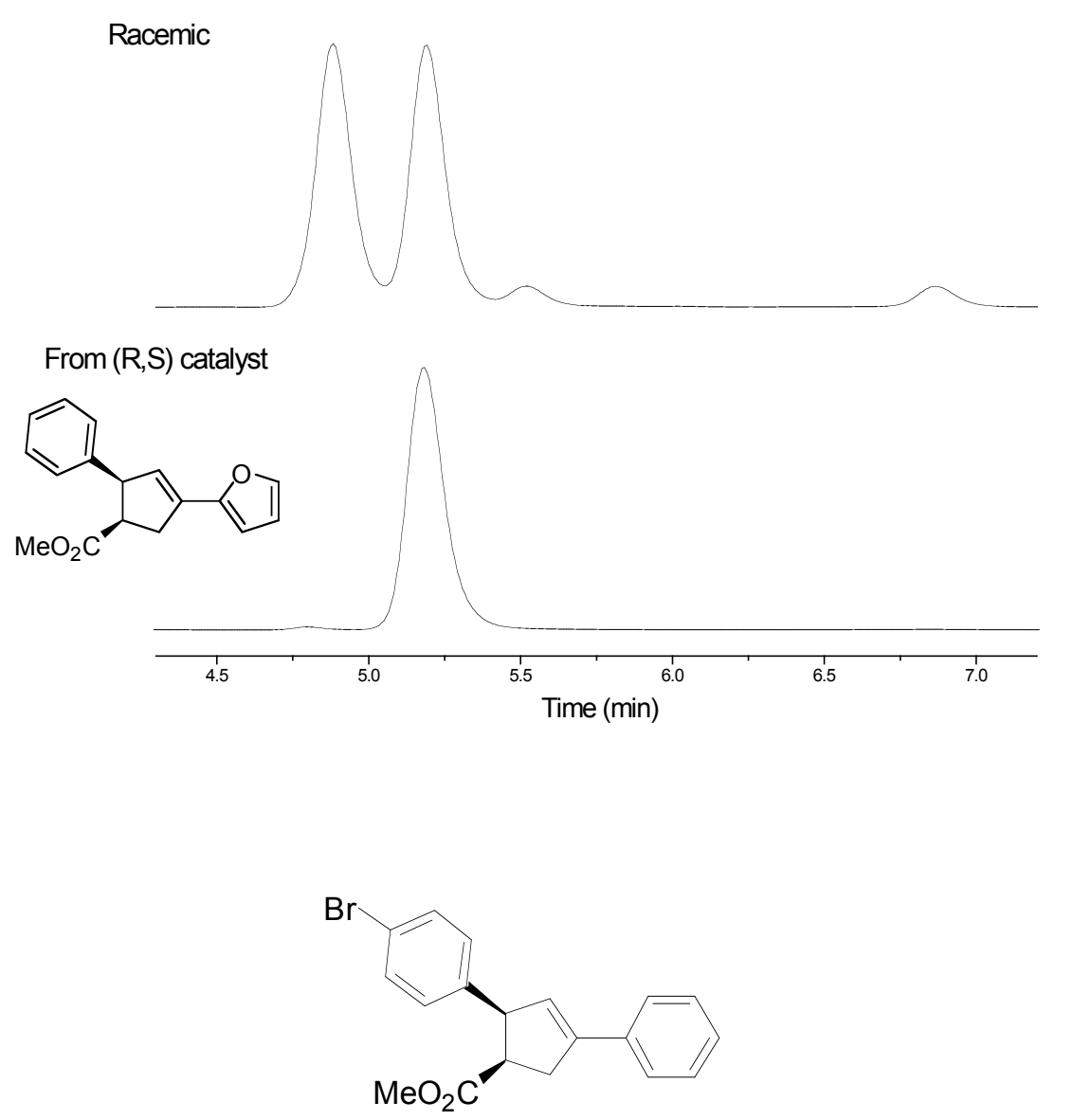

cis-3(S)-(4-Bromophenyl)-4(R)-methoxycarbonyl-1-phenylcyclopent-1-ene (Table 1, entry 5). Prepared according to the general procedure from 4-bromocinnamaldehyde and trans-methyl-4oxo-4-phenylbut-2-enoate using $10 \mathrm{~mol} \% 1$ as the catalyst in $93 \%$ yield $(6: 1 \mathrm{dr})$ as a light yellow solid. $[\alpha]_{\mathrm{D}}{ }^{20}\left(\mathrm{c} 1.03, \mathrm{CHCl}_{3}\right)$ : +113.2; mp: $67-68{ }^{\circ} \mathrm{C} ;{ }^{1} \mathrm{H} \mathrm{NMR}\left(400 \mathrm{MHz}, \mathrm{CDCl}_{3}\right) \delta 7.57-$ $7.54(\mathrm{ad}, 2 \mathrm{H}), 7.52-7.31(\mathrm{~m}, 5 \mathrm{H}), 7.20-7.04(\mathrm{ad}, 2 \mathrm{H}), 6.12(\mathrm{~s}, 1 \mathrm{H}), 4.41-4.37$ (dt, $1 \mathrm{H}, J=9.8$, $2.6 \mathrm{~Hz}), 3.78-3.73(\mathrm{~m}, 1 \mathrm{H}), 3.46-3.40(\mathrm{~m}, 1 \mathrm{H}), 3.32(\mathrm{~s}, 3 \mathrm{H}), 2.96-2.90(\mathrm{dd}, 1 \mathrm{H}, J=11.6,9.1$ $\mathrm{Hz}) ;{ }^{13} \mathrm{C}$ NMR $\left(100 \mathrm{MHz}, \mathrm{CDCl}_{3}\right) \delta 173.1,143.2,139.3,135.4,131.8,131.3,130.4,129.5$, $128.7,128.1,126.2,126.0,125.9,121.1,54.6^{*}, 54.0,52.3^{*}, 51.5,48.6,37.1^{*}, 34.6$; IR (thin film) v 2947, 1736, 1641, 1487, 1446, 1434, 1200, $1168 \mathrm{~cm}^{-1}$; HRMS (EI) for $\mathrm{C}_{19} \mathrm{H}_{17} \mathrm{BrO}_{2}$ calcd. 
$\left(\mathrm{M}^{+}\right)$: 356.0412, found: 356.0400; 99\% ee (major, cis), 67\% ee (minor, trans) as determined by HPLC (AD-H, 60:1 hexanes:EtOH), $t_{\mathrm{r}}($ major $)=9.5$ and $16.3 \mathrm{~min}, t_{\mathrm{r}}($ minor $)=10.8$ and $13.2 \mathrm{~min}$.
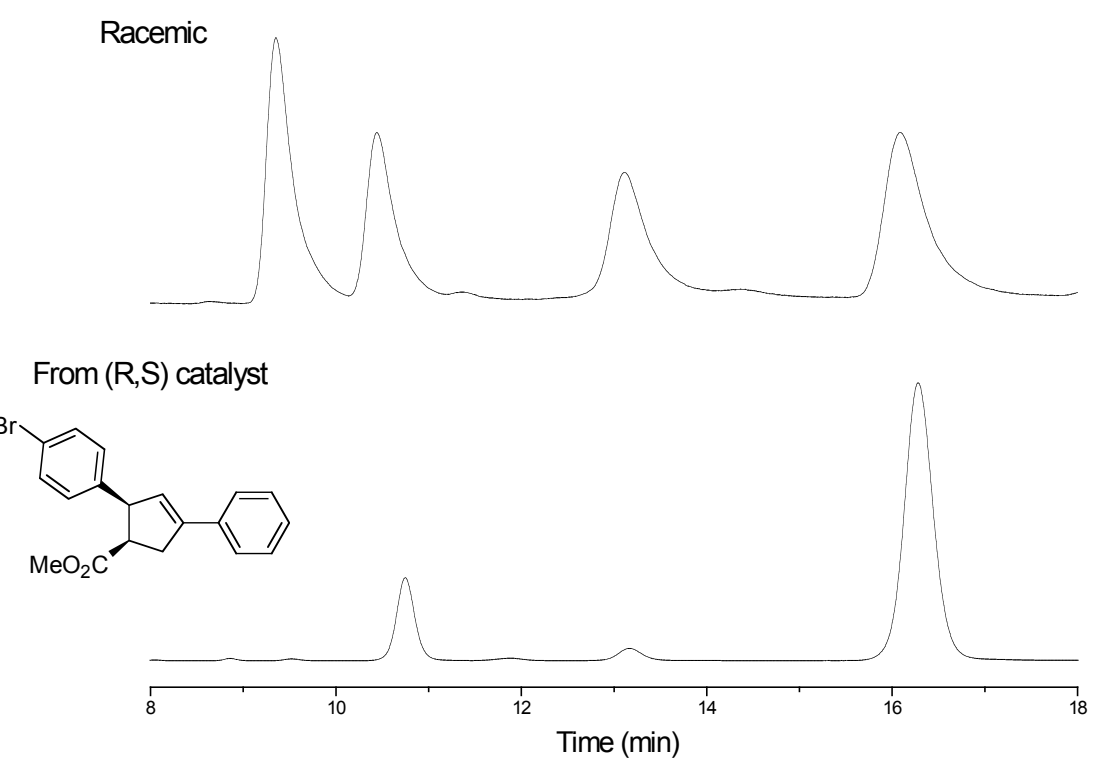

NOE Experiment
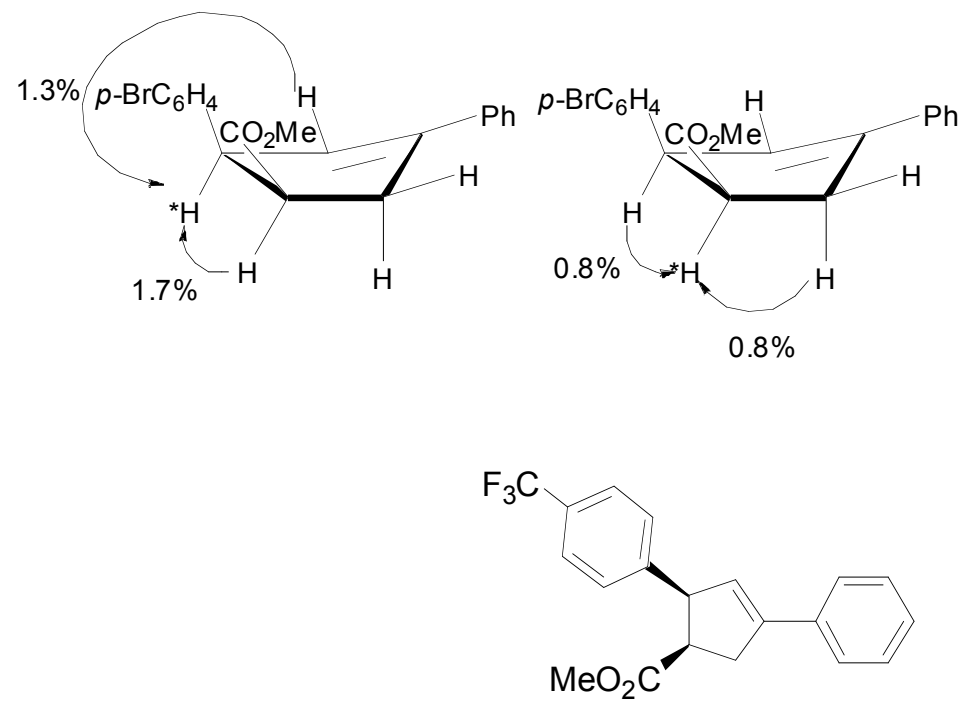

cis-4(R)-Methoxycarbonyl-1-phenyl-3(S)-(4-(trifluoromethy)phenyl)cyclopent-1-ene (Table 1, entry 6). Prepared according to the general procedure from 4-trifluoromethylcinnamaldehyde and trans-methyl-4-oxo-4-phenylbut-2-enoate using $10 \mathrm{~mol} \% \mathbf{1}$ as the catalyst in $68 \%$ yield (4:1 dr) as a white solid. $[\alpha]_{\mathrm{D}}{ }^{20}\left(\mathrm{c} 1.00, \mathrm{CHCl}_{3}\right):+116.7 ; \mathrm{mp}: 54-55{ }^{\circ} \mathrm{C} ;{ }^{1} \mathrm{H} \mathrm{NMR}\left(400 \mathrm{MHz}, \mathrm{CDCl}_{3}\right) \delta$ 7.63-7.53 (m, 4H), 7.45-7.31 (m, 5H), $6.16(\mathrm{~s}, 1 \mathrm{H}), 4.51-4.49(\mathrm{~d}, 1 \mathrm{H}, J=9.8 \mathrm{~Hz}), 3.86-3.78$ 
(m, 1H), 3.51-3.45 (m, 1H), $3.29(\mathrm{~s}, 3 \mathrm{H}), 3.01-2.95(\mathrm{dd}, 1 \mathrm{H}, J=11.6,9.1 \mathrm{~Hz}) ;{ }^{13} \mathrm{C}$ NMR $(100$ $\left.\mathrm{MHz}, \mathrm{CDCl}_{3}\right) \delta 173.1,143.6,135.4,129.1,128.8,128.3,128.1,126.1,126.0,125.9,125.2$, $125.1,54.9^{*}, 54.3,52.2^{*}, 51.5,48.7,37.1^{*}, 34.7$; IR (thin film) v 2950, 1738, 1618, 1326, 1165 , $1123 \mathrm{~cm}^{-1}$; HRMS (EI) for $\mathrm{C}_{20} \mathrm{H}_{17} \mathrm{~F}_{3} \mathrm{O}_{2}$ calcd. $\left(\mathrm{M}^{+}\right)$: 346.1181, found: 346.1180; 98\% ee (major, cis), 67\% ee (minor, trans) as determined by HPLC (AD-H, 60:1 hexanes:EtOH), $t_{\mathrm{r}}$ (major) $=6.8$ and $10.9 \mathrm{~min}, t_{\mathrm{r}}$ (minor) $=7.5$ and $9.3 \mathrm{~min}$.

Racemic

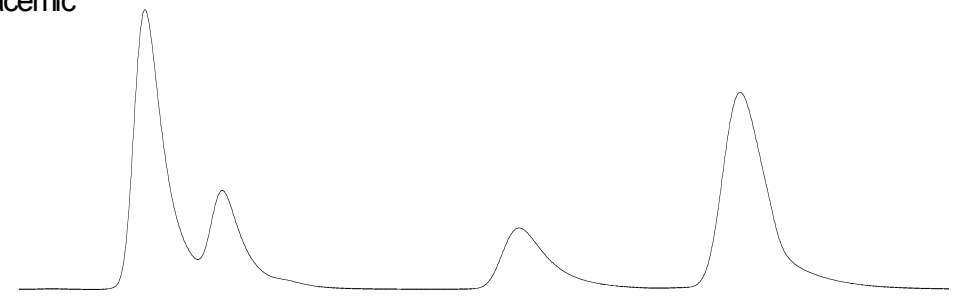

From $(R, S)$ catalyst
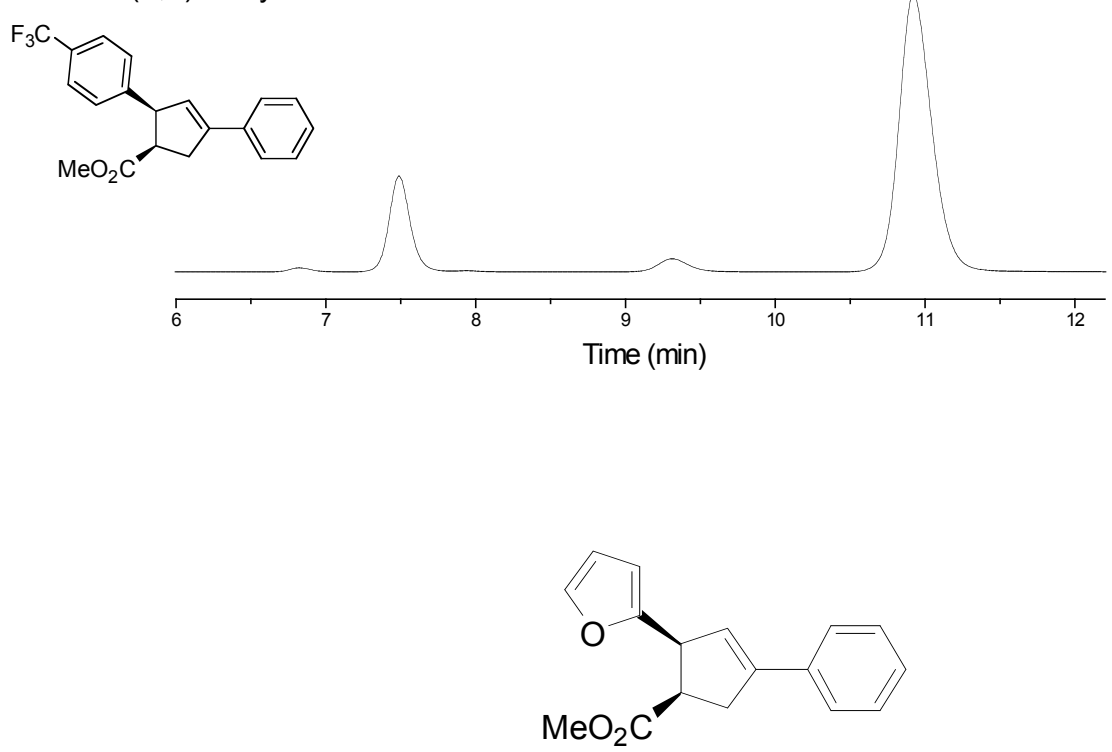

cis-3(S)-(Furan-2-yl)-4(R)-methoxycarbonyl-1-phenylcyclopent-1-ene (Table 1, entry 7). Prepared according to the general procedure from trans-3-(2-furyl)acrolein and trans-methyl-4oxo-4-phenylbut-2-enoate using $10 \mathrm{~mol} \% 1$ as the catalyst in 53\% yield $(5: 1 \mathrm{dr})$ as a yellow solid. $[\alpha]_{\mathrm{D}}{ }^{20}\left(\mathrm{c} 1.03, \mathrm{CHCl}_{3}\right):+135.8$; mp: 70-71 ${ }^{\circ} \mathrm{C} ;{ }^{1} \mathrm{H}$ NMR $\left(400 \mathrm{MHz}, \mathrm{CDCl}_{3}\right) \delta$ 7.52-7.50 (m, 2H), 7.39-7.28 (m, 4H), 6.29-6.27 (dd, 1H, J=2.3, $1.8 \mathrm{~Hz}), 6.10-6.06(\mathrm{~m}, 2 \mathrm{H}), 4.52-4.49$ (dt, $1 \mathrm{H}, J=10.6,2.5 \mathrm{~Hz}), 3.66-3.61(\mathrm{dd}, 1 \mathrm{H}, J=13.4,8.8 \mathrm{~Hz}), 3.51(\mathrm{~s}, 3 \mathrm{H}), 3.42-3.38(\mathrm{~m}, 1 \mathrm{H})$, 2.91-2.85 (dd, $1 \mathrm{H}, J=11.4,8.8 \mathrm{~Hz}) ;{ }^{13} \mathrm{C} \mathrm{NMR}\left(100 \mathrm{MHz}, \mathrm{CDCl}_{3}\right) \delta 173.4,154.1,143.5,142.0$, 
135.6, 128.7, 128.1, 126.1, 123.6, 110.5, 107.0, 51.9, 47.8, 47.5, 34.6; IR (thin film) v 2949, 1736, 1638, 1496, 1435, 1358, 1263, 1216, $1173 \mathrm{~cm}^{-1}$; HRMS (EI) for $\mathrm{C}_{17} \mathrm{H}_{16} \mathrm{O}_{3}$ calcd. $\left(\mathrm{M}^{+}\right)$: 269.1099, found: 268.1090; 99\% ee (major, cis), 82\% ee (minor, trans) as determined by HPLC $(\mathrm{AD}-\mathrm{H}, 60: 1$ hexanes:EtOH $), t_{\mathrm{r}}($ major $)=11.2$ and $18.8 \mathrm{~min}, t_{\mathrm{r}}($ minor $)=10.5$ and $14.9 \min$.

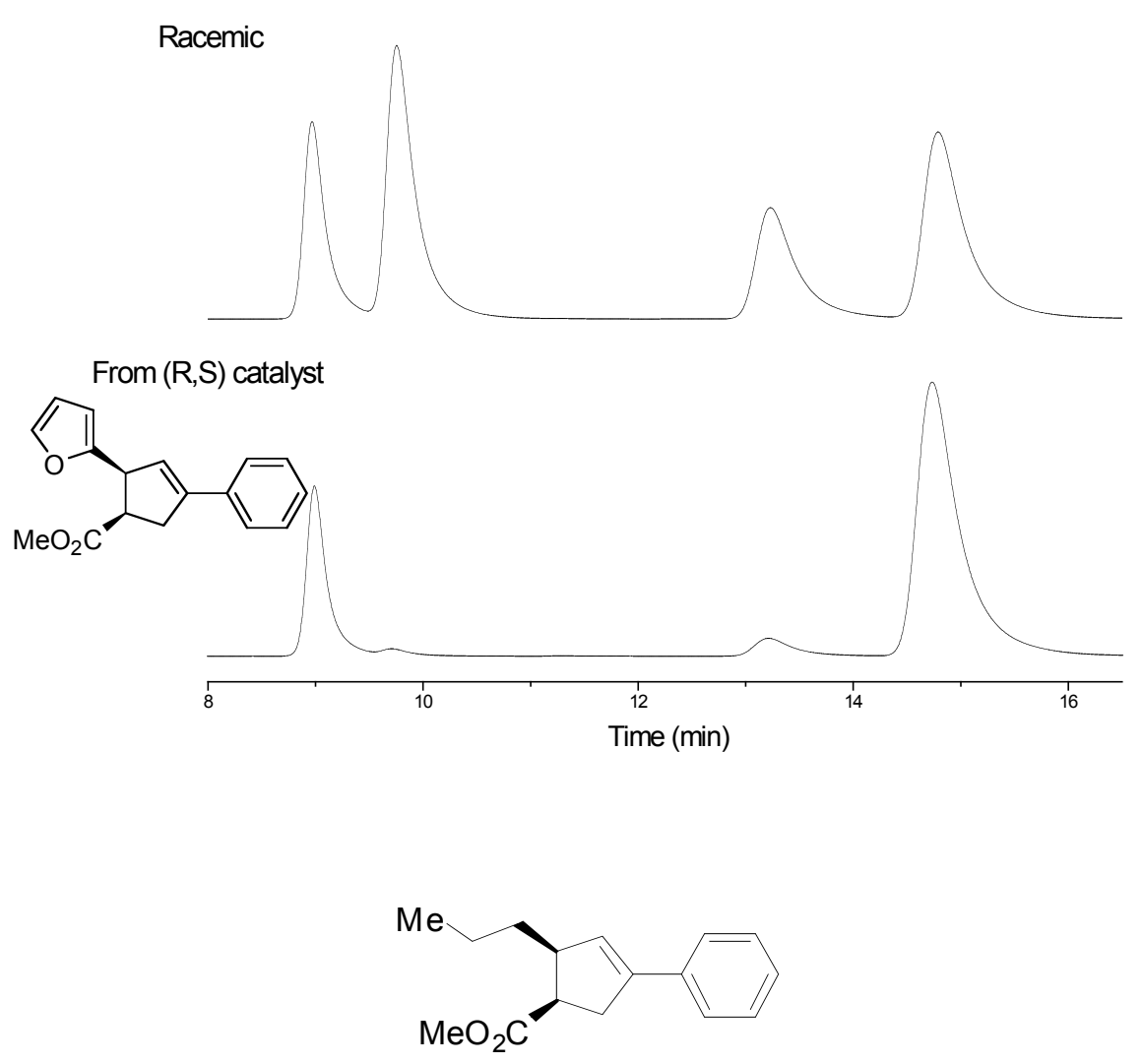

cis-4(R)-Methoxycarbonyl-1-phenyl-3(S)-propylcyclopent-1-ene (Table 1, entry 8). Prepared according to the general procedure but heated at $60{ }^{\circ} \mathrm{C}$ for an additional $20 \mathrm{~h}$ from trans-2-hexen1-al and trans-methyl-4-oxo-4-phenylbut-2-enoate using $10 \mathrm{~mol} \% \mathbf{1}$ as the catalyst in $25 \%$ yield $(14: 1 \mathrm{dr})$ as yellow liquid. $[\alpha]_{\mathrm{D}}{ }^{20}\left(\mathrm{c} 0.96, \mathrm{CHCl}_{3}\right):+150.0 ;{ }^{1} \mathrm{H} \mathrm{NMR}\left(400 \mathrm{MHz}, \mathrm{CDCl}_{3}\right) \delta 7.46-$ $7.44(\mathrm{ad}, 2 \mathrm{H}), 7.35-7.25(\mathrm{~m}, 3 \mathrm{H}), 6.18(\mathrm{~s}, 1 \mathrm{H}), 3.74(\mathrm{~s}, 3 \mathrm{H}), 3.43-3.39(\mathrm{dd}, 1 \mathrm{H}, J=13.2,8.9$ $\mathrm{Hz}), 3.25-3.21$ (m, 1H), 3.19-3.12 (br, 1H), 2.81-2.75 (dd, 1H, J = 11.3, 8.7 Hz), 1.42-1.30 (m, 4H), 0.95-0.91 (m, 3H); ${ }^{13} \mathrm{C}$ NMR (100 MHz, $\left.\mathrm{CDCl}_{3}\right) \delta 174.7,140.9,136.2,128.6,127.9,127.6$, 125.8, 51.7, 47.7, 47.1, 34.5, 33.5, 21.1, 14.5; IR (thin film) v 2955, 2929, 2871, 1737, 1447, 1435, 1195, $1176 \mathrm{~cm}^{-1}$; HRMS (EI) for $\mathrm{C}_{16} \mathrm{H}_{20} \mathrm{O}_{2}$ calcd. $\left(\mathrm{M}^{+}\right)$: 244.1463, found: $244.1468 ; 96 \%$ 
ee (major, cis), 32\% ee (minor, trans) as determined by HPLC (AD-H, 60:1 hexanes:EtOH), $t_{\mathrm{r}}$ $($ major $)=4.8$ and $8.4 \mathrm{~min}, t_{\mathrm{r}}($ minor $)=5.3$ and $5.7 \mathrm{~min}$.

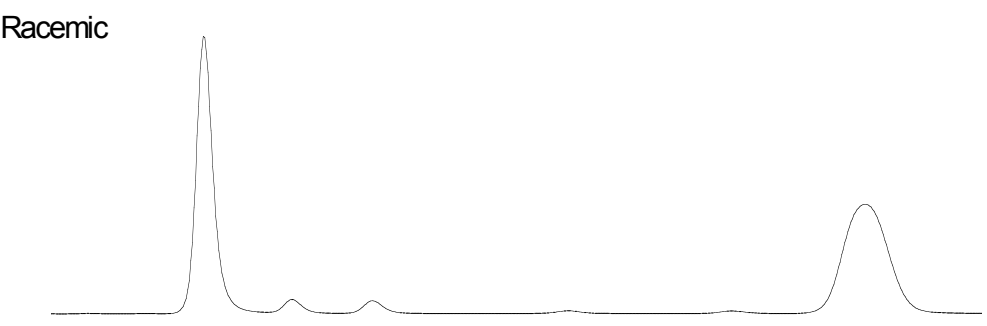

From $(R, S)$ catalyst

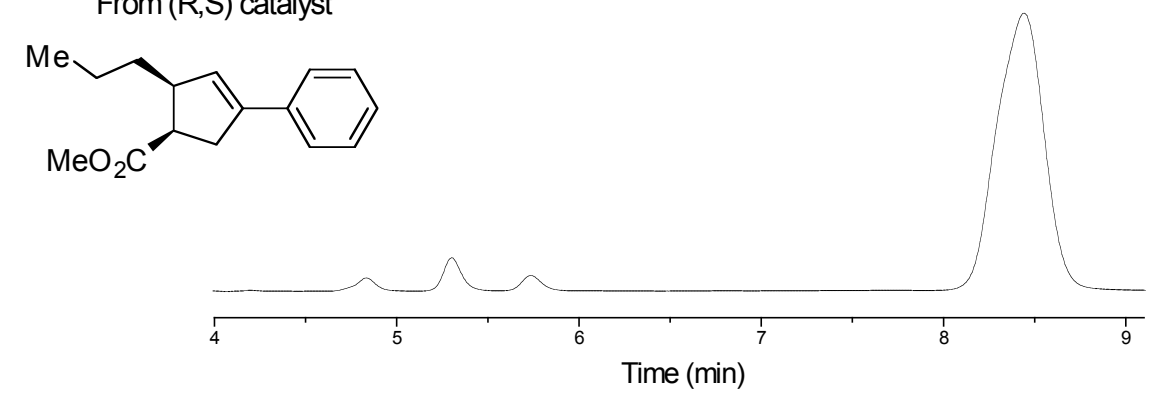

NOE Experiment
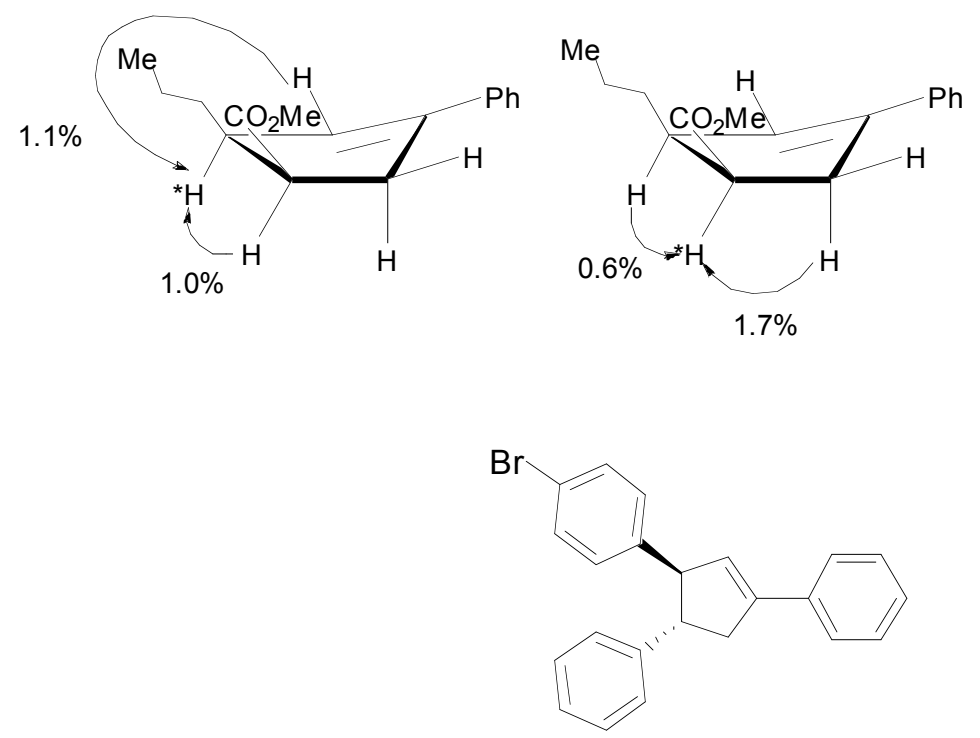

trans-3(S)-(4-Bromophenyl)-1,4(S)-diphenyl-cyclopent-1-ene (trans-15). Prepared according to the general procedure from 4-bromocinnamaldehyde and trans-chalcone using $10 \mathrm{~mol} \% \mathbf{1}$ as the catalyst in $69 \%$ yield $(9: 1 \mathrm{dr})$ as light yellow liquid. $[\alpha]_{\mathrm{D}}{ }^{20}\left(\mathrm{c} 1.17, \mathrm{CHCl}_{3}\right):+56.9 ;{ }^{1} \mathrm{H} \mathrm{NMR}$ $\left(400 \mathrm{MHz}, \mathrm{CDCl}_{3}\right) \delta$ 7.56-7.54 (m, 2H), 7.42-7.37 (m, 4H), 7.34-7.30 (m, 3H), 7.27-7.22 (m, 
3H), 7.04-7.00 (m, 2H), $6.22(\mathrm{~s}, 1 \mathrm{H}), 4.11-4.09(\mathrm{~m}, 1 \mathrm{H}), 3.40-3.31(\mathrm{~m}, 2 \mathrm{H}), 3.05-3.03(\mathrm{~m}, 1 \mathrm{H})$; ${ }^{13} \mathrm{C}$ NMR $\left(100 \mathrm{MHz}, \mathrm{CDCl}_{3}\right) \delta$ 145.0, 144.1, 142.9, 135.9, 131.7, 129.4, 128.8, 128.7, 127.9, $127.8,127.5,126.6,126.0,120.4,60.5,55.0,42.1$; IR (thin film) v 3026, 2924, 2848, 1600, 1486, 1446, 1404, $1261 \mathrm{~cm}^{-1}$; HRMS (EI) for $\mathrm{C}_{23} \mathrm{H}_{19} \mathrm{Br}$ calcd. $\left(\mathrm{M}^{+}\right)$: 374.0670, found: 374.0662; $55 \%$ ee (major, trans), $99 \%$ ee (minor, cis) as determined by HPLC (AD-H, 12:1 hexanes:iPrOH $), t_{\mathrm{r}}($ major $)=5.0$ and $5.4 \min , t_{\mathrm{r}}($ minor $)=4.2$ and $4.4 \mathrm{~min}$.

Racemic

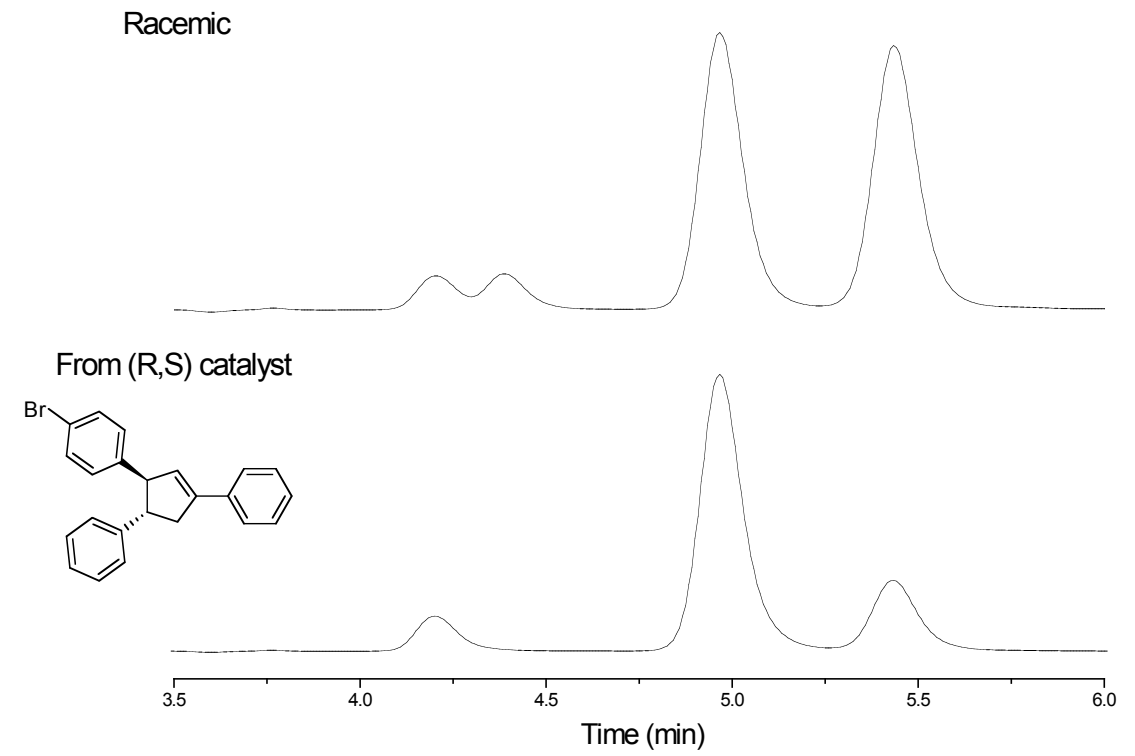

NOE Experiment

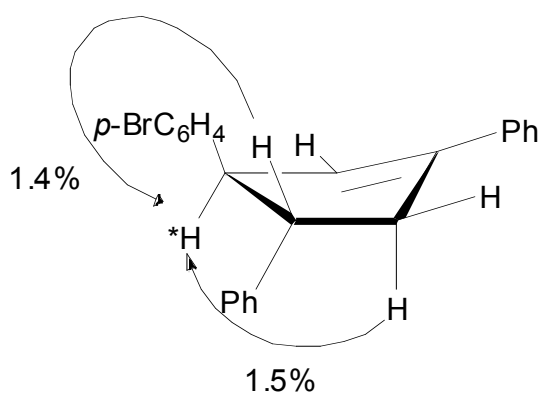

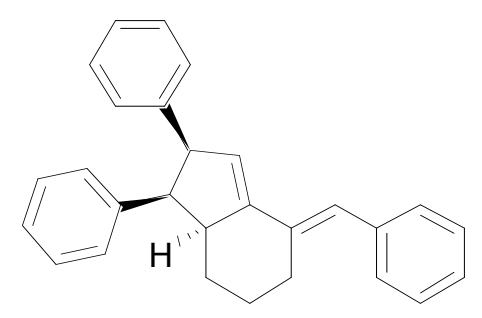

(1R,2S,7aS,E)-4-Benzylidene-1,2-diphenyl-2,4,5,6,7,7a-hexahydro-1H-indene

(cis-14).

Prepared according to the general procedure from cinnamaldehyde and trans,transdibenzylidenecyclo-hexanone using $10 \mathrm{~mol} \% 1$ as the catalyst in $45 \%$ yield $(>20: 1 \mathrm{dr})$ as a yellow solid. $[\alpha]_{\mathrm{D}}{ }^{20}\left(\mathrm{c} 1.03, \mathrm{CHCl}_{3}\right):+213.9 ; \mathrm{mp}=108-109{ }^{\circ} \mathrm{C} ;{ }^{1} \mathrm{H} \mathrm{NMR}\left(400 \mathrm{MHz}, \mathrm{CDCl}_{3}\right) \delta$ 7.41-7.14 (m, 15H), 6.85-6.84 (ad, 1H), 5.93 (s, 1H), 4.13-4.10 (ad, 1H), 3.04-2.89 (m, 3H), 
2.35-2.27 (m, 1H), 2.08-1.98 (ad, 1H), 1.91-1.87 (ad, 1H), 1.44-1.33 (m, 2H); ${ }^{13} \mathrm{C}$ NMR (100 $\left.\mathrm{MHz}, \mathrm{CDCl}_{3}\right) \delta 146.9,144.9,142.7,137.7,137.0,129.7,128.5,128.4,128.3,128.3,127.7$, 126.7, 126.5, 126.5, 125.5, 124.1, 65.5, 58.5, 54.1, 32.4, 29.4, 25.7; IR (thin film) v 3026, 2926, 1702, 1600, 1494, $1450 \mathrm{~cm}^{-1}$; HRMS (EI) for $\mathrm{C}_{28} \mathrm{H}_{26}$ calcd. $\left(\mathrm{M}^{+}\right)$: 362.2035, found: 362.2048; $72 \%$ ee (major, cis) as determined by SFC (AS-H, 70\% $\left.\mathrm{MeOH}: \mathrm{CO}_{2}\right), t_{\mathrm{r}}$ (major) $=8.5$ and 9.8 $\min$.

NOE experiment

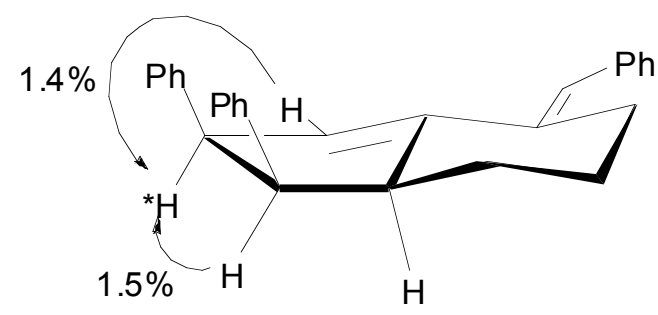

NHC-Catalyzed Oxy-Cope Reactions and Control Experiments

(a)
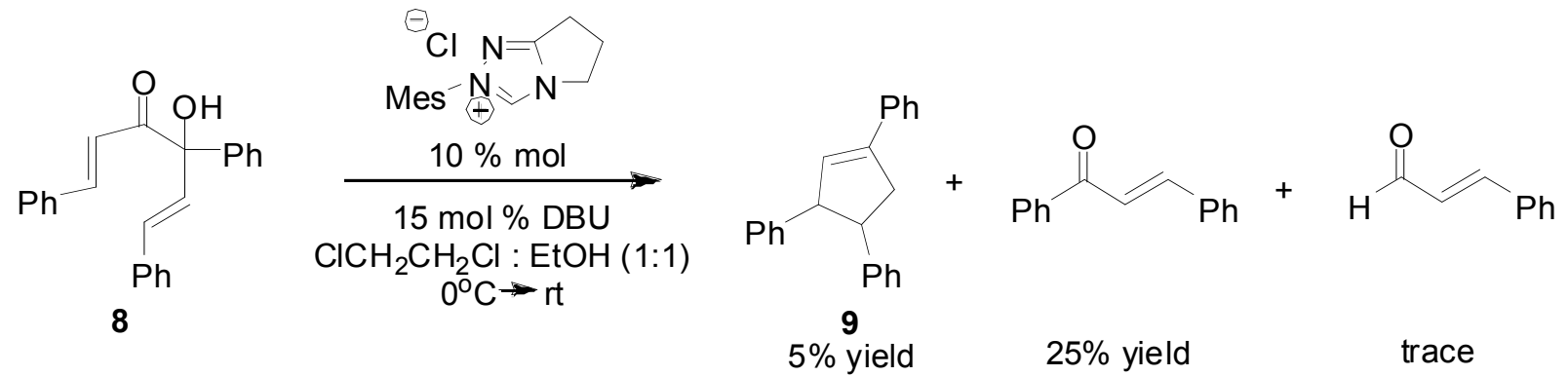

Into an oven dried $10.0 \mathrm{~mL}$ flask was added the triazolium catalyst (6 mg, $0.021 \mathrm{mmol})$ and 4hydroxy-1,4,6-triphenyl-hexa-1,5-dien-3-one $(\mathbf{8})(72 \mathrm{mg}, 0.21 \mathrm{mmol})$ was added as a solution in $2 \mathrm{~mL}$ dichloroethane. The reaction mixture was stirred at $0{ }^{\circ} \mathrm{C}$ for $15 \mathrm{~min}$, before $\mathrm{DBU}(4.7 \mu \mathrm{L}$, $4.8 \mathrm{mg}, 0.032 \mathrm{mmol}$ ) was added. After stirring overnight at $\mathrm{rt}$, the reaction mixture was concentrated under reduced pressure and the residue was purified by PTLC (10:1 hexanes: EtOAc). 
(b)

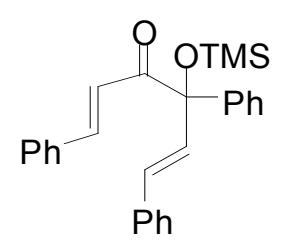

10

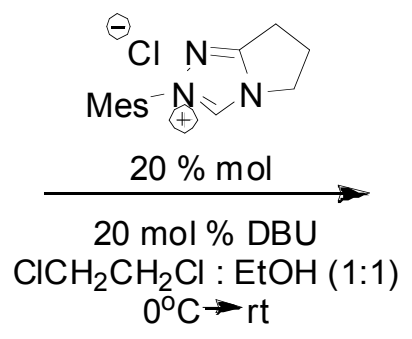

Retro silyl benzoin/Stetter product
$5 \%$ yield

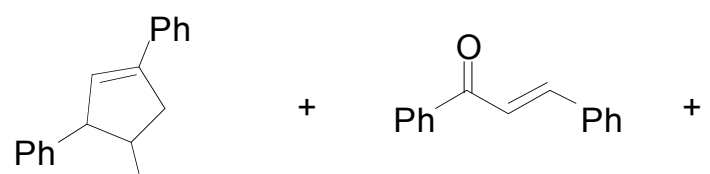

$6.5 \%$ yield<smiles>CCOC(=O)CC(c1ccccc1)C(CC(=O)c1ccccc1)c1ccccc1</smiles>

12 $24 \%$ yield

Into an oven dried $10.0 \mathrm{~mL}$ flask was added the triazolium catalyst $(7.5 \mathrm{mg}, 0.029 \mathrm{mmol})$ and 1,4,6-triphenyl-4-trimethylsilanyl-hexa-1,5-dien-3-one (10) (59.2 mg, $0.143 \mathrm{mmol})$ was added as a solution in $2 \mathrm{~mL} \mathrm{1:1} \mathrm{EtOH:} \mathrm{DCE}$. The reaction mixture was stirred at $0{ }^{\circ} \mathrm{C}$ for $15 \mathrm{~min}$, before DBU ( $4 \mu \mathrm{L}, 3.35 \mathrm{mg}, 0.022 \mathrm{mmol}$ ) was added. After stirring overnight at rt, the reaction mixture was concentrated under the reduced pressure, and residue was purified by PTLC (15:1 hexanes: EtOAc).

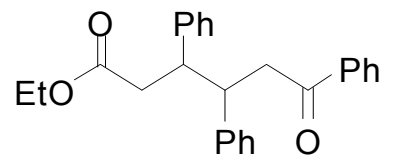

1,3,6-Triphenyl-hex-5-ene-1,4-dione (12). Pale yellow oil. ${ }^{1} \mathrm{H} \mathrm{NMR}\left(\mathrm{CDCl}_{3}, 400 \mathrm{MHz}\right) \delta 8.01-$ $7.99(2 \mathrm{H}, \mathrm{m}), 7.67(1 \mathrm{H}, \mathrm{d}, J=16 \mathrm{~Hz}), 7.59-7.57(1 \mathrm{H}, \mathrm{m}), 7.51-7.45(5 \mathrm{H}, \mathrm{m}), 7.37-7.34(7 \mathrm{H}, \mathrm{m})$, 7.31-7.26 (1H, m), $6.82(1 \mathrm{H}, \mathrm{d}, J=16 \mathrm{~Hz}), 4.75(1 \mathrm{H}, \mathrm{dd}, J=4,9.6 \mathrm{~Hz}), 4.13(1 \mathrm{H}, \mathrm{dd}, J=9.6$, $18 \mathrm{~Hz}), 3.23(1 \mathrm{H}, \mathrm{dd}, J=4,18 \mathrm{~Hz}) ;{ }^{13} \mathrm{C} \mathrm{NMR}\left(\mathrm{CDCl}_{3}, 100 \mathrm{MHz}\right) \delta 198.3,198.0,143.5,138.4$, $136.8,134.7,133.4,130.6,129.4,129.0,128.8,128.5,128.4,127.8,125.2$, 52.5, 42.7; IR (thin film) $v$ 3059, 2917, 1683, 1610, 1449, 753, $719 \mathrm{~cm}^{-1}$; HRMS (EI) $[\mathrm{M}]^{+}$calcd. for $\mathrm{C}_{24} \mathrm{H}_{20} \mathrm{O}_{2}$ 340.1463, found, 340.1470.<smiles>O=C(CC(Pc1ccccc1)C(=O)c1ccccc1)c1ccccc1</smiles> 
6-Oxo-3,4,6-triphenyl-hexanoic acid ethyl ester (retro silyl-benzoin/Stetter product). Pale yellow oil. ${ }^{1} \mathrm{H} \mathrm{NMR}\left(\mathrm{CDCl}_{3}, 400 \mathrm{MHz}\right) \delta 7.89-7.86(2 \mathrm{H}, \mathrm{m}), \quad 7.57-7.53(1 \mathrm{H}, \mathrm{m}), \quad 7.45-7.41$ (2H, m), 7.20-7.13 (6H, m), 7.96-7.91 (4H, m), 4.01-3.93 (2H, m), 3.81-3.76 (1H, m), 3.62$3.56(1 \mathrm{H}, \mathrm{m}), 3.41-3.30(2 \mathrm{H}, \mathrm{m}), 2.78(1 \mathrm{H}, \mathrm{dd}, J=6.4,15.6 \mathrm{~Hz}), 2.66(1 \mathrm{H}, \mathrm{dd}, J=9.2,15.6 \mathrm{~Hz})$, $1.21(1 \mathrm{H}, \mathrm{s}), 1.07(3 \mathrm{H}, \mathrm{t}, J=7.2 \mathrm{~Hz}) ;{ }^{13} \mathrm{C} \mathrm{NMR}\left(\mathrm{CDCl}_{3}, 100 \mathrm{MHz}\right) \delta 198.4,172.2,140.9,140.4$, $137.0,133.0,128.9,128.5,128.0,127.8,127.8,126.6,126.5,60.3,46.4,45.1,41.7,38.3,14.0$ $\mathrm{cm}^{-1}$; IR (thin film) v 3028, 2979, 1731, 1685, 1450, 750, $700 \mathrm{~cm}^{-1}$; HRMS (ESI) $[\mathrm{M}+\mathrm{Na}]^{+}$calcd. for $\mathrm{C}_{26} \mathrm{H}_{26} \mathrm{O}_{3} 409.1780$, found, 409.1777 .

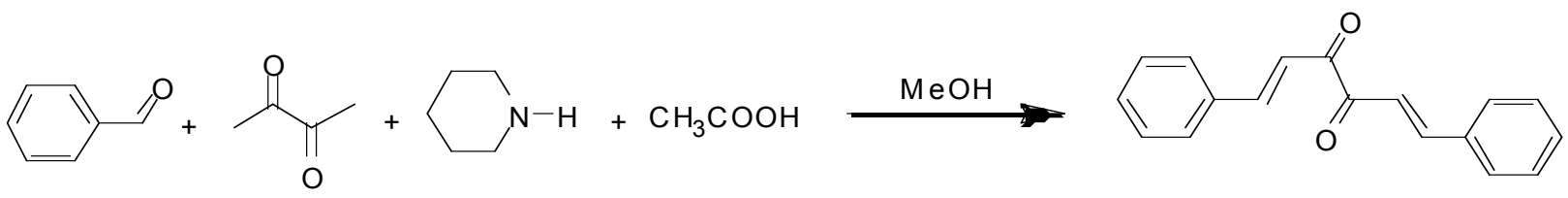

1,6-Diphenyl-hexa-1,5-diene-3,4-dione. ${ }^{1}$ Piperidine $(0.6 \mathrm{~mL}, 0.51 \mathrm{~g}, 60 \mathrm{mmol})$ and glacial $\mathrm{AcOH}(0.36 \mathrm{~mL}, 60 \mathrm{mmol})$ were added to a stirred solution of 2,3-butanedione $(2.64 \mathrm{~mL}, 2.6 \mathrm{~g}$, $30.2 \mathrm{mmol})$ and benzaldehyde $(14.5 \mathrm{~mL}, 15.12 \mathrm{~g}, 142.4 \mathrm{mmol})$ in $\mathrm{MeOH}(15 \mathrm{~mL})$ and the mixture heated to reflux for $5 \mathrm{~h}$, after which volatile compounds were removed in vacuo. The remaining oil was placed in a freezer overnight and the orange crystals were filtered to give the product $(1.28 \mathrm{~g}, 3.5 \%) . \mathrm{mp}=159-161{ }^{\circ} \mathrm{C} ;{ }^{1} \mathrm{H} \mathrm{NMR}\left(\mathrm{CDCl}_{3}, 400 \mathrm{MHz}\right) \delta 7.88(2 \mathrm{H}, \mathrm{d}, J=16 \mathrm{~Hz})$, 7.69-7.65 (4H, m), $7.50(2 \mathrm{H}, \mathrm{d}, J=16 \mathrm{~Hz}), \quad 7.47-1.43(6 \mathrm{H}, \mathrm{m}) ;{ }^{13} \mathrm{C} \mathrm{NMR}\left(\mathrm{CDCl}_{3}, 100 \mathrm{MHz}\right) \delta$ 189.0, 147.8, 134.3, 131.4, 129.0, 129.0, 119.5; IR (thin film) v 3059, 1668, 1606, 1447, 987, 727, $688 \mathrm{~cm}^{-1}$; HRMS (EI) calcd. for $\mathrm{C}_{18} \mathrm{H}_{14} \mathrm{O}_{2}[\mathrm{M}]^{+}$262.0994, found, 262.0986.
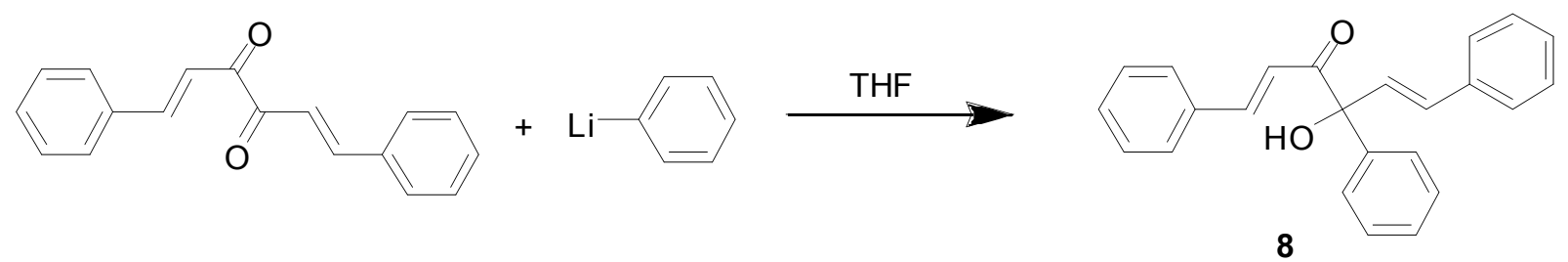

4-Hydroxy-1,4,6-triphenyl-hexa-1,5-dien-3-one (8). 1,6-Diphenyl-hexa-1,5-diene-3,4-dione (414 mg, $1.58 \mathrm{mmol}$ ) was dissolved in $16 \mathrm{~mL}$ THF and cooled to $-78{ }^{\circ} \mathrm{C}$ and phenyllithium $(1.8$ $\mathrm{M}, 0.87 \mathrm{~mL}, 1.58 \mathrm{mmol}$ ) was added. After stirring at $-78{ }^{\circ} \mathrm{C}$ for $30 \mathrm{~min}$, the reaction was diluted

(1) Constable, E.C.; Harverson, P. Polyhedron 1999, 18, 3093-3016. 
with $10 \mathrm{~mL}$ EtOAc and poured into $15 \mathrm{~mL}$ sat aq $\mathrm{NH}_{4} \mathrm{Cl}$. The aqueous layer was extracted with an additional $3 \times 15 \mathrm{~mL}$ EtOAc. The combined organic extracts were washed with $15 \mathrm{~mL}$ brine, dried over $\mathrm{Na}_{2} \mathrm{SO}_{4}$. After filtration and concentration, the residue was purified by silica chromatography (20:1 hexanes: EtOAc) to give $8(265.5 \mathrm{mg}, 50 \%)$ as a yellow oil. ${ }^{1} \mathrm{H}$ NMR $\left(\mathrm{CDCl}_{3}, 400 \mathrm{MHz}\right) \delta 7.86(1 \mathrm{H}, \mathrm{d}, J=15.6 \mathrm{~Hz}), 7.52-7.47(6 \mathrm{H}, \mathrm{m}), 7.43-7.34$ (8H, m), 7.30$7.28(1 \mathrm{H}, \mathrm{m}), 7.08(1 \mathrm{H}, \mathrm{d}, J=16 \mathrm{~Hz}), 6.87(1 \mathrm{H}, \mathrm{d}, J=16 \mathrm{~Hz}), \quad 6.84(1 \mathrm{H}, \mathrm{d}, J=15.6 \mathrm{~Hz}), 5.02$ $(1 \mathrm{H}, \mathrm{s}) ;{ }^{13} \mathrm{C} \mathrm{NMR}\left(\mathrm{CDCl}_{3}, 100 \mathrm{MHz}\right) \delta 196.8,145.7,141.0,136.3,134.0,132.9,131.1,128.9$, 128.8, 128.7, 128.6, 128.6, 128.5, 128.5, 128.4, 128.1, 127.6, 127.3, 127.0, 126.9, 126.9, 120.0, 82.4; IR (thin film) v 3439, 3059, 3026, 1681, 1607, 1065, 749, $697 \mathrm{~cm}^{-1}$; HRMS (ESI) calcd. for $\mathrm{C}_{24} \mathrm{H}_{20} \mathrm{O}_{2}[\mathrm{M}+\mathrm{Na}]^{+}$363.1361, found, 363.1352.

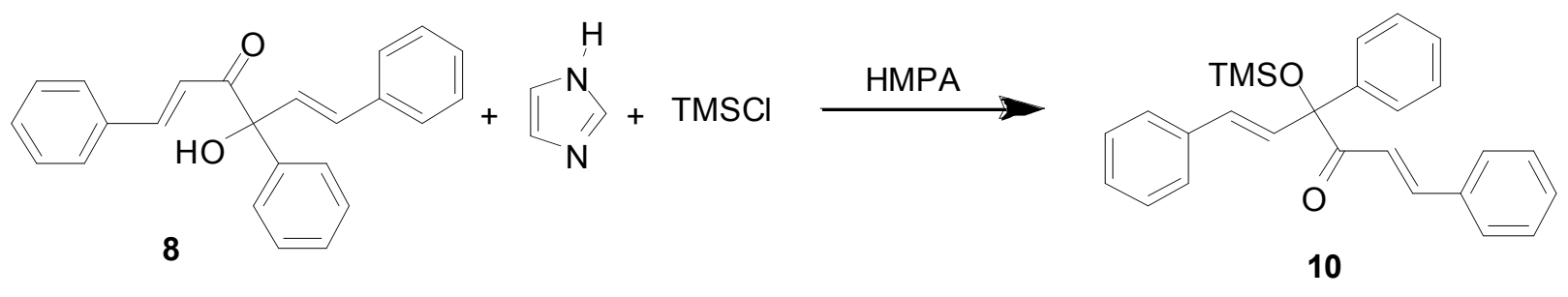

1,4,6-Triphenyl-4-trimethylsilanyl-hexa-1,5-dien-3-one (10). Hydroxy ketone 8 (265.5 mg, $0.78 \mathrm{mmol}$ ) was dissolved in $2.5 \mathrm{~mL}$ hexamethylphosphoramide (HMPA) at rt. Imidazole (212.4 $\mathrm{mg}, 3.12 \mathrm{mmol})$ and $\mathrm{TMSCl}(0.4 \mathrm{~mL}, 340.0 \mathrm{mg}, 3.12 \mathrm{mmol})$ were added. After stirring overnight, the reaction mixture was poured into $5 \mathrm{~mL} \mathrm{pH} 7$ buffer and extracted with $3 \times 5 \mathrm{~mL}$ $\mathrm{Et}_{2} \mathrm{O}$. The combined organics were washed with $5 \mathrm{~mL}$ brine, dried over $\mathrm{Na}_{2} \mathrm{SO}_{4}$ and concentrated under reduced pressure. Purification by chromatography on silica (10: 1 hexanes: EtOAc) to give ketone $10(224.0 \mathrm{mg}, 70 \%)$ as a yellow oil. ${ }^{1} \mathrm{H} \mathrm{NMR}\left(\mathrm{CDCl}_{3}, 400 \mathrm{MHz}\right) \delta 7.75(1 \mathrm{H}, \mathrm{d}, J=16$ $\mathrm{Hz}), 7.56-7.53$ (4H, m), 7.45-7.41 (2H, m), 7.40-7.32 (7H, m), 7.29-7.28 (2H, m), 7.20 (1H, $\mathrm{d}, J=16 \mathrm{~Hz}), 7.02(1 \mathrm{H}, \mathrm{d}, J=16 \mathrm{~Hz}), 6.57(1 \mathrm{H}, \mathrm{d}, J=16 \mathrm{~Hz}), 0.20(9 \mathrm{H}, \mathrm{s}) ;{ }^{13} \mathrm{C} \mathrm{NMR}\left(\mathrm{CDCl}_{3}\right.$, $100 \mathrm{MHz}) \delta 198.1,143.2,141.0,136.1,134.4,133.5,130.6,130.1,128.5,128.3,128.1,128.0$, 127.7, 127.5, 126.7, 126.4, 121.1, 84.7, 1.8; IR (thin film) 3059, 3026, 2956, 1689, 1611, 1251, 842, 753, $703 \mathrm{~cm}^{-1}$; HRMS (ESI) calcd. for $\mathrm{C}_{27} \mathrm{H}_{28} \mathrm{O}_{2} \mathrm{Si}[\mathrm{M}+\mathrm{Na}]^{+}$435.1756, found, 435.1752.

\section{General procedure for the preparation of $\alpha, \beta$-unsaturated aldehydes}


All $\alpha, \beta$-unsaturated aldehydes were prepared according to literature procedures. ${ }^{2,3}$ The corresponding aryl iodides and bromides (1.0 equiv) are allowed to react with acrolein diethyl acetal (3.0 equiv) in the presence of ${ }^{\mathrm{n}} \mathrm{BuNOAc}$ (2 equiv), $\mathrm{K}_{2} \mathrm{CO}_{3}$ (1.5 equiv), $\mathrm{KCl}$ (1.0 equiv), $\mathrm{Pd}(\mathrm{OAc})_{2}\left(0.03\right.$ equiv) and $\mathrm{DMF}(0.25 \mathrm{M})$ at $90{ }^{\circ} \mathrm{C}$ for $2-6 \mathrm{~h}$, followed by addition of $2 \mathrm{~N} \mathrm{HCl}$ to the reaction mixture. The reaction mixture was extracted with $\mathrm{Et}_{2} \mathrm{O}$, and the organic layer was concentrated and purified by column chromatography (9:1 hexanes:EtOAc) to afford the corresponding aldehydes.

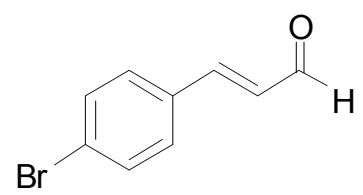

4-bromocinnamaldehyde. ${ }^{1} \mathrm{H} \mathrm{NMR}\left(400 \mathrm{MHz}, \mathrm{CDCl}_{3}\right) \delta 9.72-9.70(\mathrm{~d}, 1 \mathrm{H}, J=7.5 \mathrm{~Hz}), 7.60-$ $7.56(\mathrm{~m}, 2 \mathrm{H}), 7.45-7.41(\mathrm{~m}, 3 \mathrm{H}), 6.74-6.68(\mathrm{dd}, 1 \mathrm{H}, J=16.0,7.5 \mathrm{~Hz}) ;{ }^{13} \mathrm{C} \mathrm{NMR}(100 \mathrm{MHz}$, $\left.\mathrm{CDCl}_{3}\right) \delta 193.7,151.4,133.1,132.6,130.0,129.2,125.9$. Other spectral data was identical to the literature values.

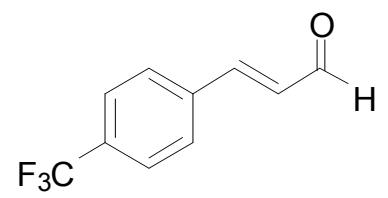

4-trifluoromethylcinnamaldehyde. ${ }^{1} \mathrm{H}$ NMR $\left(400 \mathrm{MHz}, \mathrm{CDCl}_{3}\right) \delta 9.78-9.75(\mathrm{~d}, 1 \mathrm{H}, J=7.7$ $\mathrm{Hz}), 7.72-7.67(\mathrm{~m}, 4 \mathrm{H}), 7.54-7.50(\mathrm{~d}, 2 \mathrm{H}, J=16.1 \mathrm{~Hz}), 6.82-6.76(\mathrm{dd}, 1 \mathrm{H}, J=16.0,7.5 \mathrm{~Hz})$; ${ }^{13} \mathrm{C} \mathrm{NMR}\left(100 \mathrm{MHz}, \mathrm{CDCl}_{3}\right) \delta 193.5,150.6,130.7,128.8,126.3,126.2$. Other spectral data was identical to the literature values.

\section{Preparation of 4-oxoenonates}

All 4-oxoenonates were prepared according to literature protocols. ${ }^{4}$

(2) Battistuzzi, G.; Cacchi, S.; Fabrizi, G. Org. Lett. 2003, 5, 777-780.

(3) Fevig, J.; Cacciola, J.; Alexander, R. S.; Knabb, R. M.; Lam, G. N.; Wong, P. C.; Wexler, R. R. Bioorg. Med. Chem. Lett. 1998, 8, 3143-3148.

(4) He, M.; Uc, G. J.; Bode, J. W. J. Am. Chem. Soc. 2006, 128, 15088-15089. 


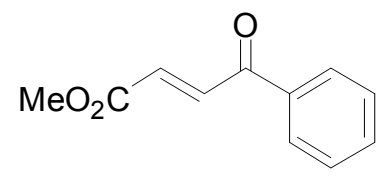

trans-methyl-4-oxo-4-phenylbut-2-enoate (3). ${ }^{5}{ }^{1} \mathrm{H}$ NMR $\left(400 \mathrm{MHz}, \mathrm{CDCl}_{3}\right) \delta 8.02-8.00(\mathrm{~m}$, 2H), 7.00-7.91 (d, 1H, $J=15.5 \mathrm{~Hz}), 7.65-7.61(\mathrm{~m}, 1 \mathrm{H}), 7.54-7.50(\mathrm{~m}, 2 \mathrm{H}), 6.92-6.88(\mathrm{~d}, 1 \mathrm{H}, J$ $=15.6 \mathrm{~Hz}), 3.85(\mathrm{~s}, 3 \mathrm{H}) ;{ }^{13} \mathrm{C} \mathrm{NMR}\left(100 \mathrm{MHz}, \mathrm{CDCl}_{3}\right) \delta 189.6,166.2,136.8,134.1,132.3,129.1$, 120.0, 52.6. Other spectral data was identical to the literature values.

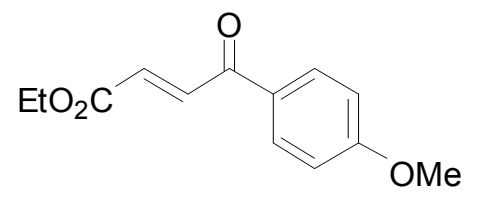

trans-ethyl-4-(4-methoxyphneyl)-4-oxobut-2-enoate. ${ }^{6}{ }^{1} \mathrm{H}$ NMR $\left(400 \mathrm{MHz}, \mathrm{CDCl}_{3}\right) \delta 8.02-$ $8.00(\mathrm{~d}, 2 \mathrm{H}, J=8.9 \mathrm{~Hz}), 7.99-7.90$ (d, 1H, $J=15.5 \mathrm{~Hz}), 6.99-6.97$ (d, 2H, $J=8.9 \mathrm{~Hz}), 6.89-$ $6.85(\mathrm{~d}, 1 \mathrm{H}, J=15.5 \mathrm{~Hz}), 4.32-4.27$ (q, 2H, $J=7.1 \mathrm{~Hz}), 3.89-3.87$ (s, 3H), 1.36-1.33 (t, 3H, $J=$ $7.1 \mathrm{~Hz}) ;{ }^{13} \mathrm{C} \mathrm{NMR}\left(100 \mathrm{MHz}, \mathrm{CDCl}_{3}\right) \delta$ 187.8, 165.9, 164.4, 136.7, 132.0, 131.5, 129.9, 114.3, $61.5,55.8,14.4$. Other spectral data was identical to the literature values.

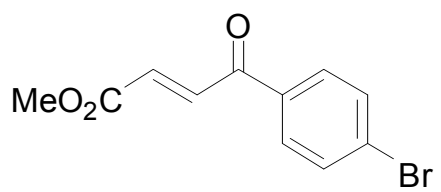

trans-methyl-4-(4-bromophneyl)-4-oxobut-2-enoate. ${ }^{7,8}{ }^{1} \mathrm{H}$ NMR $\left(400 \mathrm{MHz}, \mathrm{CDCl}_{3}\right) \delta 7.90-$ $7.86(\mathrm{~m}, 3 \mathrm{H}), 7.69-7.66(\mathrm{~m}, 2 \mathrm{H}), 6.94-6.90(\mathrm{~d}, 1 \mathrm{H}, J=15.5 \mathrm{~Hz}), 3.86(\mathrm{~s}, 3 \mathrm{H}) ;{ }^{13} \mathrm{C}$ NMR $(100$ $\left.\mathrm{MHz}, \mathrm{CDCl}_{3}\right) \delta 188.5,166.1,136.1,135.5,132.8,132.5,130.5,129.5,52.7$. Other spectral data was identical to the literature values.

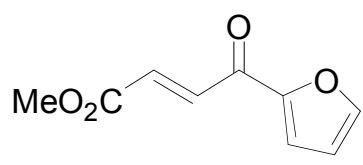

(5) Chien, C. S.; Kawasaki, T.; Sakamoto, M.; Tamura, Y.; Kita, Y. Chemical \& Pharmaceutical Bulletin 1985, 33, 2743-2749.

(6) Clive, D. L. J.; Hisaindee, S.; Colrart, D. M. J. Org. Chem. 2003, 68, 9247-9254.

(7) Xie, Y.-Y.; Chen, Z.-C. Synthetic Communications 2002, 32, 1875-1879.

(8) Runcie, K. A.; Taylor, R. J. K. Chem. Comm. 2002, 974-975. 
trans-methyl-4-(4-furan-2-yl)-4-oxobut-2-enoate. ${ }^{6,9}{ }^{1} \mathrm{H}$ NMR (400 MHz, $\left.\mathrm{CDCl}_{3}\right) \delta$ 7.80-7.76 $(\mathrm{d}, 1 \mathrm{H}, J=15.5 \mathrm{~Hz}), 7.71-7.70(\mathrm{t}, 1 \mathrm{H}, J=0.8 \mathrm{~Hz}), 7.40-7.39$ (d, 1H, $J=3.7 \mathrm{~Hz}), 7.01-6.98$ (d, $1 \mathrm{H}, J=15.7 \mathrm{~Hz}), 6.64-6.63(\mathrm{q}, 1 \mathrm{H}, J=1.7 \mathrm{~Hz}), 3.85(\mathrm{~s}, 3 \mathrm{H}) ;{ }^{13} \mathrm{C} \mathrm{NMR}\left(100 \mathrm{MHz}, \mathrm{CDCl}_{3}\right) \delta$ $176.6,166.1,153.0,148.1,135.9,131.9,119.9,113.2,52.6$. Other spectral data was identical to the literature values.

\section{Preparation of $\alpha, \alpha^{\prime}$-bis(substituted benzylidene) cycloalkane}

trans,trans-Dibenzylidenecyclohexanone was prepared according to the literature procedure. ${ }^{10}$ The synthesis was achieved by the reaction of cyclohexanone (1.0 equiv) with benzaldehyde (2.0 equiv) using $\mathrm{Cu}(\mathrm{OTf})_{2}$ as catalyst.

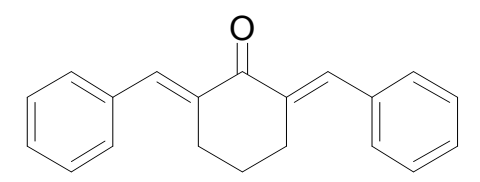

trans,trans-dibenzylidenecyclohexanone (13). ${ }^{1} \mathrm{H}$ NMR $\left(400 \mathrm{MHz}, \mathrm{CDCl}_{3}\right) \delta 7.82(\mathrm{~s}, 2 \mathrm{H})$, 7.50-7.33 (m, 10H), 2.97-2.93 (m, 4H), 1.84-1.79 (m, 2H); $\left.{ }^{13} \mathrm{C} \mathrm{NMR} \mathrm{(100} \mathrm{MHz,} \mathrm{CDCl}_{3}\right) \delta$ $190.6,137.2,136.4,136.2,130.6,128.8,128.6,28.7,23.2$. Other spectral data was identical to the literature values.

Determination of the relative and absolute stereochemistry of the cyclopentene products The stereochemistry was determined by single crystal x-ray analysis of the product derived from 4-bromocinnamaldehyde (see above for characterization datum): A colorless crystal of approximate dimensions $0.4 \times 0.05 \times 0.04 \mathrm{~mm}$ was mounted on a glass fiber and transferred to a Bruker CCD platform diffractometer. The SMART ${ }^{11}$ program was used to determine the unite cell parameters and data collection (20 sec: frame, $0.3 \mathrm{deg}$.: frame for a sphere of diffraction data). The data were collected at room temperature. The raw frame data were processed using SAINT $^{12}$ program. The absorption correction was applied using program SADABS ${ }^{13}$. The

(9) Matsumoto, T.; Ohishi, M.; Inoue, S. J. Org. Chem. 1985, 50, 603-606.

(10) Li, J.; Su, W.; Li, N. Synthetic Communications 2005, 35, 3037-3043.

(11) SMART Software Users Guide, Version 5.1, Bruker Analytical X-ray Systems, Inc., Madison, WI 1999.

(12) SAINT Software Users Guide, Version 5.1, Bruker Analytical X-ray Systems, Inc., Madison, WI 1999. 
structure was solved by direct methods and refined on F2 by full-matrix least-squares techniques. Hydrogen atoms were theoretically added. At convergence, GOF $=1.207$ for 206 variables refined to $\mathrm{R} 1=0.0632$ for 1415 reflections with $\mathrm{I}>2 \sigma(\mathrm{I})$. The absolute structure was determined from the Flack parameters ${ }^{14}-0.02$ (2). See the corresponding CIF file for further information.
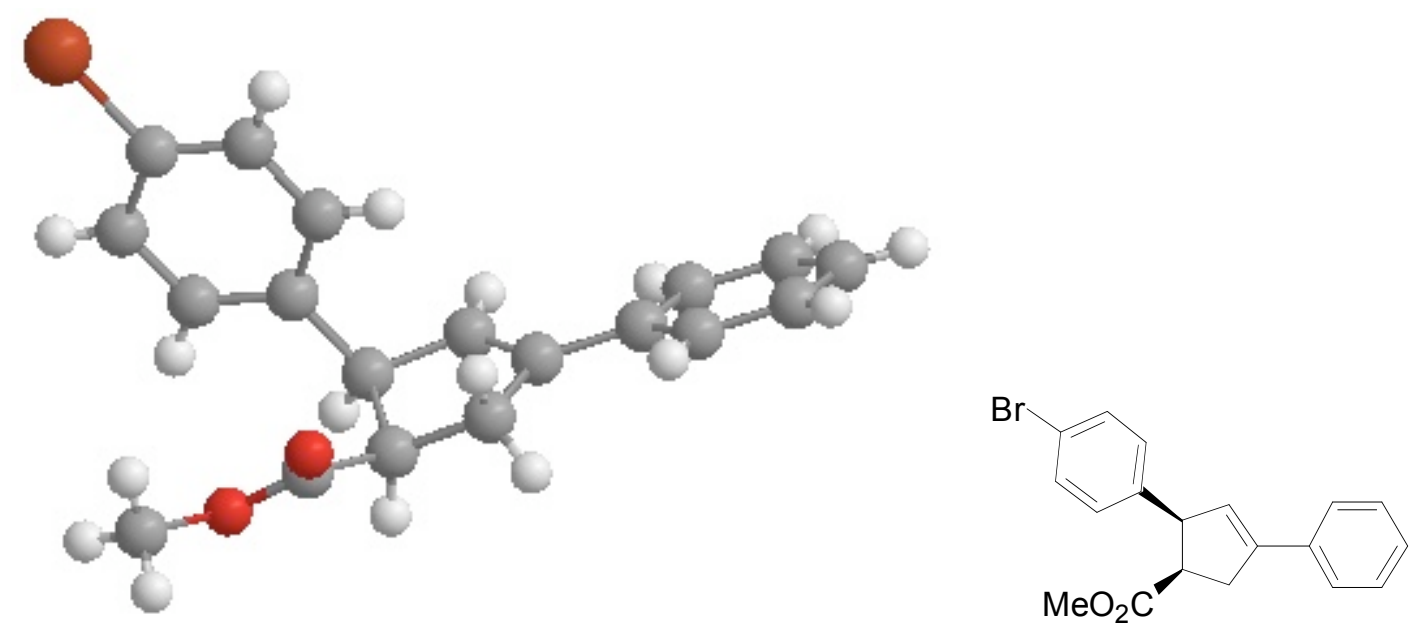

(13) Sheldrick, G. M. SADABS, Version 2.05, Bruker Analytical X-ray Systerms, Inc.; Madison, WI 2001.

(14) Flack, H. D., Acta Cryst. A 1983, 39, 876-881. 


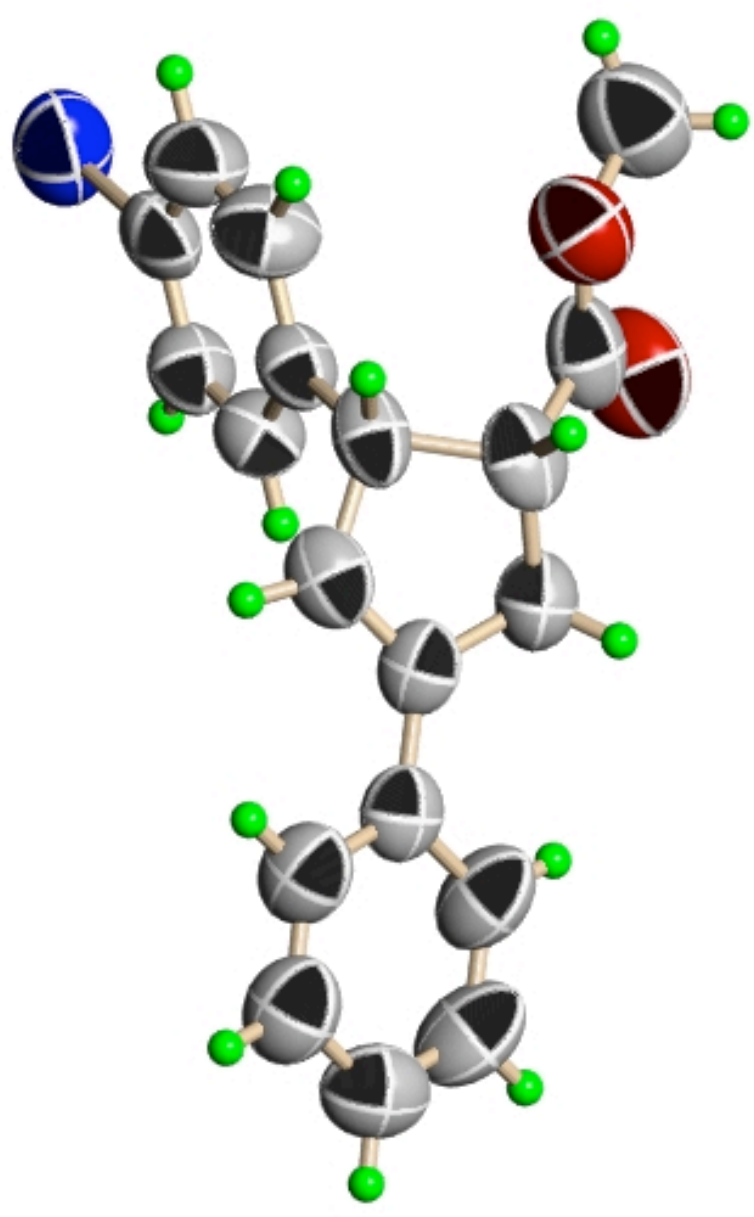

Figure 1. ORTEP representation (50\% probability level) of cis-3(S)-(4-bromophenyl)-4(R)methoxycarbonyl-1-phenylcyclopent-1-ene. 